University of Nebraska - Lincoln

DigitalCommons@University of Nebraska - Lincoln

\title{
PHYLOGENY OF THE ASCARIDOIDEA (NEMATODA: ASCARIDIDA) BASED ON THREE GENES AND MORPHOLOGY: HYPOTHESES OF STRUCTURAL AND SEQUENCE EVOLUTION
}

\author{
Steven A. Nadler \\ University of California - Davis, sanadler@ucdavis.edu \\ Deborah S. S. Hudspeth \\ Northern Illinois University
}

Follow this and additional works at: https://digitalcommons.unl.edu/parasitologyfacpubs

Part of the Parasitology Commons

Nadler, Steven A. and Hudspeth, Deborah S. S., "PHYLOGENY OF THE ASCARIDOIDEA (NEMATODA: ASCARIDIDA) BASED ON THREE GENES AND MORPHOLOGY: HYPOTHESES OF STRUCTURAL AND SEQUENCE EVOLUTION" (2000). Faculty Publications from the Harold W. Manter Laboratory of Parasitology. 708.

https://digitalcommons.unl.edu/parasitologyfacpubs/708

This Article is brought to you for free and open access by the Parasitology, Harold W. Manter Laboratory of at DigitalCommons@University of Nebraska - Lincoln. It has been accepted for inclusion in Faculty Publications from the Harold W. Manter Laboratory of Parasitology by an authorized administrator of DigitalCommons@University of Nebraska - Lincoln. 


\title{
PHYLOGENY OF THE ASCARIDOIDEA (NEMATODA: ASCARIDIDA) BASED ON THREE GENES AND MORPHOLOGY: HYPOTHESES OF STRUCTURAL AND SEQUENCE EVOLUTION
}

\author{
Steven A. Nadler and Deborah S. S. Hudspeth* \\ Department of Nematology, University of California, Davis, California 95616-8668
}

\begin{abstract}
Ascaridoid nematodes parasitize the gastrointestinal tract of vertebrate definitive hosts and are represented by more than 50 described genera. We used 582 nucleotides ( $83 \%$ of the coding sequence) of the mitochondrial gene cytochrome oxidase subunit 2, in combination with published small- and large-subunit nuclear rDNA sequences (2,557 characters) and morphological data (20 characters), to produce a phylogenetic hypothesis for representatives of this superfamily. This combined evidence phylogeny strongly supported clades that, with 1 exception, were consistent with Fagerholm's 1991 classification. Parsimony mapping of character states on the combined evidence tree was used to develop hypotheses for the evolution of morphological, life history, and amino acid characters. This analysis of character evolution revealed that certain key features that have been used by previous workers for developing taxonomic and evolutionary hypotheses represent plesiomorphic states. Cytochrome oxidase subunit 2 nucleotides show a strong compositional bias to $\mathrm{A}+\mathrm{T}$ and a substitution bias to thymine. These biases are most apparent at third positions of codons and 4 -fold degenerate sites, which is consistent with the nonrandom substitution pattern of $\mathrm{A}+\mathrm{T}$ pressure. Despite nucleotide bias, cytochrome oxidase amino acid sequences show conservation and retention of critical functional residues, as inferred from comparisons to other organisms.
\end{abstract}

Perhaps due to their importance as disease agents, large size, and availability, e.g., Ascaris suum, species of ascaridoids are among the most thoroughly studied nematode parasites of vertebrates. For example, members of this superfamily have been used for studies of respiratory biochemistry (Saz and Weil, 1960; Komuniecki et al., 1993), molecular genetics (Neuhaus et al., 1987; Kageyama, 1998), immunology (Jones et al., 1994), reproductive biology (Von Beneden, 1883; Foor, 1970), comparative morphology (Fagerholm, 1989, 1991; Hugot et al., 1991), development (Boveri, 1899; Pilitt et al., 1981), life cycles (Huizinga, 1967; Klöser et al., 1992; Køie and Fagerholm, 1995), population genetics (Anderson et al., 1993; Nascetti et al., 1993; Nadler, 1996), and pathology (Beaver, 1956; Overstreet and Meyer, 1981; Kazacos, 1986). In contrast, much less is known about the evolutionary history of taxa in this superfamily, although certain organisms, e.g., Ascaris, Anisakis, have been studied in detail at the microevolutionary level (Paggi et al., 1991; Anderson et al., 1993, 1995; Anderson and Jaenike, 1997).

Structural features of ascaridoids, particularly external ones, show considerable variation among genera and, in some cases, species. Likewise, their life cycles also show a diversity of patterns. However, although many general features of ascaridoid life cycles have been established, detailed studies have been limited to relatively few species, and in some cases, recent investigations have yielded new findings for such thoroughly studied species as A. suum (Murrell et al., 1997). Evolutionary scenarios to explain observed patterns of life-cycle variation have frequently been proposed. For example, it has been debated whether the monoxenous (1-host) or heteroxenous life cycle is ancestral for the group (Fülleborn, 1927; Chitwood and Chitwood, 1950; Mozgovoi, 1953; Sprent, 1954; Chabaud, 1955; Anderson, 1988). Testing such competing evolutionary scenarios requires a phylogenetic framework for comparison.

Most evolutionary hypotheses for ascaridoids were devel-

Received 7 May 1999; revised 25 August 1999; accepted 25 August 1999.

* Department of Biological Sciences, Northern Illinois University, DeKalb, Illinois 60115. oped prior to the widespread use of cladistic analysis, and these hypotheses were typically based on interpretation of variation in 1 or a few key structures or life history features (Gibson, 1983; Sprent, 1983). More rarely, the assumption of host-parasite coevolution (Osche, 1963; Gibson, 1983) was used to develop evolutionary hypotheses. Emphasis on different key features (or differences in their interpretation) by different investigators led to different hypotheses for transformation and polarity of character states, and conflicting hypotheses of relationships (Mozgovoi, 1953; Hartwich, 1954, 1957, 1974; Osche, 1958, 1963; Gibson, 1983; Sprent, 1983; Fagerholm, 1991). Predictably, differences in evolutionary hypotheses have also led to instability of ascaridoid classification. For example, Hsu's (1933) classification emphasized the presence or absence of the ventriculus in forming 2 major groups (genera in terrestrial mammals [excepting Toxocara], and genera in fish, birds, aquatic reptiles, and aquatic mammals), whereas Hartwich (1974) emphasized the structure of the secretory-excretory system in combination with the concepts of Chabaud (1965) in organizing ascaridoids into 5 families and 8 subfamilies. More recently, nucleotide (nt) sequences have provided data for developing phylogenetic hypotheses for some ascaridoids (Nadler, 1992, 1995; Nadler and Hudspeth, 1998; Zhu et al., 1998), and trees based on ribosomal DNA sequences are mostly consistent with a more recent classification of the group (Fagerholm, 1991). However, rDNA gene trees have failed to provide entirely satisfactory resolution for certain questions (Nadler and Hudspeth, 1998; Zhu et al., 1998) and represent inferences based on a single locus.

In the present study, phylogenetic relationships among 20 ascaridoid taxa, comprising 14 genera, were inferred using a combined analysis of previously published nuclear-encoded rDNA sequences (Nadler and Hudspeth, 1998), mitochondrially encoded cytochrome oxidase subunit $2(\operatorname{cox} 2)$ sequences, and morphological data. This combined evidence approach (Eernisse and Kluge, 1993; Kluge, 1998) is interpreted to represent the best phylogenetic estimate, given the available data. The $\operatorname{cox} 2$ (nucleotide sequences abbreviated $\operatorname{cox} 2$, amino acid sequences as COII) sequence data were also analyzed separately 
to infer a tree for this gene. Due to the maternal inheritance of mitochondrial DNA (mtDNA) in most organisms, including Ascaris (Anderson, Komuniecki et al., 1995), cox2 represents a genetically independent locus from genes in the nucleus. Hypotheses for the evolution of morphological, life history, and COII data were developed relative to the tree inferred from the combined analysis. The pattern of $\operatorname{cox} 2$ substitution was also estimated using the combined analysis tree and a parsimonybased approximation method to produce a rate matrix of change.

\section{MATERIALS AND METHODS}

\section{Taxa for molecular systematics}

Studied taxa and their classification (sensu Fagerholm, 1991) included Heterocheilidae (Railliet and Henry, 1912), Heterocheilus tunicatus, Raphidascarididae (Hartwich, 1954, rank sensu Fagerholm, 1991), Goezia pelagia, Hysterothylacium fortalezae, Hysterothylacium pelagicum, Hysterothylacium reliquens, Anisakidae (Railliet and Henry, 1912), Anisakis sp., Contracaecum multipapillatum, Pseudoterranova decipiens, Terranova caballeroi, Ascarididae (Baird, 1853), Ascaris lumbricoides, A. suum, Baylisascaris procyonis, Baylisascaris transfuga, Parascaris equorum, Porrocaecum depressum, Toxocara canis, Toxascaris leoni$n a$, and Iheringascaris inquies, a genus not included by Fagerholm (1991). Based on small subunit (SSU) ribosomal DNA (rDNA) gene trees (Nadler and Hudspeth, 1998) and hypotheses of relationship based on morphological similarity (Inglis, 1965), Cruzia americana, a member of the Cosmocercoidea (Ascaridida), was included as an outgroup for the Ascaridoidea. Collection site and host data for these taxa have been reported (Nadler and Hudspeth, 1998).

\section{DNA amplification and sequencing}

Nucleic acids were extracted from frozen $(-70 \mathrm{C})$ tissue samples of body wall muscle (larger species) or from individual or pooled samples of whole adults or juveniles, as previously described (Nadler and Hudspeth, 1998). Methods for polymerase chain reaction (PCR) amplification and sequencing of nuclear rDNA were reported in Nadler and Hudspeth (1998), and these sequences deposited in GenBank (SSU sequences U94365-94383, large subunit [LSU] sequences U94749-94769). The cox2 locus was amplified by PCR using several different strategies. Amplification primers were designed based on the sequences (Okimoto et al., 1992) and mtDNA gene order of A. suum (X54253) and Caenorhabditis elegans (X54252). In an attempt to obtain complete cox2 sequences, amplification primers were designed to anneal to the transfer RNAs (tRNA-Gly, tRNA-His) flanking cox2 (in A. suum, C. elegans, and Onchocerca volvulus, AF015193), or to genes (cytochrome oxidase subunit 1 [coxl], large ribosomal-RNA, [L-rRNA]) adjacent to these tRNAs in A. suum and C. elegans. The laboratory designations for these PCR primers, their corresponding positions in complete A. suum mtDNA (accession X54253; positions in parentheses), their orientation ( $>$ forward, $<$ reverse), and their sequences are: no. 56 (L-rRNA, 12,064-12,046) <TGACTTTCTGTTAACTCCG, no. 57 (coxl, 10,295-10,315) > GGTCATAGTTACCAGTCTGAG, no. 103 (t-RNAHis, $11,319-11,300)<$ ACAAGCATTTTCACATAAAC, no. $104(\mathrm{t}-$ RNA-Gly, 10,549-10,568) > TTTTTGTACATTTGACTTCC. Most attempts to amplify the complete gene using primers flanking cox 2 were successful for the Ascaridinae (subfamily of A. suum) but not for most species from other families. Taxa that were successfully amplified by flanking primers and confirmed by sequencing included B. procyonis (primers 56/57), B. transfuga (primers 56/57), P. decipiens (primers 103/104), and T. leonina (primers 104/56). For all Ascaridida, 2 internal cox 2 primers were successfully used to amplify 629 bp (90\%) of coding sequence: no. $210(11,267-11,248)<$ CACCAACTCTTAAAATTATC, and no. $211(10,639-10,665)>$ TTTTCTAGTTATATAGATTGRTTTYAT. For the no. 210/no. 211 PCR, an initial DNA denaturation at 94 $\mathrm{C}$ for 4 min was followed by 25 cycles of PCR using Taq or Vent $\mathrm{R}_{\mathrm{R}}$ (New England Biolabs, Beverly, Massachusetts) polymerase; $94 \mathrm{C}$ for $30 \mathrm{sec}, 45 \mathrm{C}$ for $30 \mathrm{sec}$, and $72 \mathrm{C}$ for $50 \mathrm{sec}$, followed by a postamplification extension for $5 \mathrm{~min}$ at $72 \mathrm{C}$. Although PCR conditions were empirically optimized for individual templates, typical conditions for $50-\mu 1$ reactions included $300 \mathrm{ng}$ of DNA template, $4 \mathrm{mM} \mathrm{MgCl}$, and a 2 -fold concentration of the degenerate primer no. 211 (final concentration $1 \mu \mathrm{M}$ ) relative to primer no. 210. For direct sequencing, 1 of 2 methods of PCR template preparation was used. PCR products were either purified by agarose gel electrophoresis in TAE buffer, $\mathrm{pH} 8.0$ (Ausubel et al., 1989) and product recovered from gel slices using a QIAEX (Qiagen, Valencia, California) kit, or products were washed 3 times by spin filtration (Millipore Ultrafree-MC 30,000 NMWL, Bedford, Massachusetts) using TE buffer ( $\mathrm{pH}$ 8.0). Prior to sequencing, PCR templates were quantified by fluorometry using Hoechst 33258 dye and a Hoefer TKO 100 minifluorometer with TKO 130 capillary cuvette; $200-400$ fmol of PCR product was used per sequencing reaction. Direct sequencing of cox2 PCR products yielded reliable sequence data for primer no. 210 , but typically not for the degenerate primer no. 211. To obtain full-length double-stranded sequence of the amplified DNA, PCR products were cloned into pGEM-T vector (Promega, Madison, Wisconsin). For cloning, PCR products were washed 3 times with TE ( $\mathrm{pH} 8.0$ ) by spin filtration, ligated into pGEM-T vector, and used to transform DH5 $\alpha$ Escherichia coli. With the exception of the outgroup, $C$. americana, a minimum of 2 clones were sequenced for each taxon (1 for each DNA strand). Typically, clones displayed absolute complementarity, although in some cases a third clone was needed to fully verify (double-strand) the sequence. Sequencing reactions were performed manually using the Delta-Taq cycle sequencing kit (Amersham, Piscataway, New Jersey) and $\alpha^{32}$ P-dATP (specific activity $>3,000 \mathrm{Ci} / \mathrm{mmol}$ ), with annealing temperatures for the labeling and termination steps adjusted empirically for each sequencing primer. 7-Deaza-dGTP was used in cycle and termination mixes to reduce potential gel compression artifacts. Cesium chloride-purified plasmid DNA was used as template. Double-stranded cox2 sequence was obtained using 2 pGEM-T vector primers of our own design (pGEM-T 2974$2997>$ GGCCAGTGAATTGTAATACGACTC; 110-135 < GACACTATAGAATACTCAAGCTATGC) and 3 cox 2 primers for each taxon. The cox 2 primers included the PCR primer no. 210, and 2 internal priming sites with opposite orientations. The internal priming sites were found to be variable among species, therefore, 2 different sequencing primers were used for these regions: no. $20<$ TCCCTAAACTCATAACTTC, no. $21<$ TCCCTAAACTCATAACTCC, no. $332>$ CACCAGTGATATTGAAGTTACG, and no. 388 >CATCAGTGGTATTGGAGTTATG. A sequence obtained from noncloned PCR product template using primer no. 210 was included in each contig and used to confirm that clones were consistent with the products obtained directly from PCR.

\section{Sequence analysis}

The invariant $47 \mathrm{nt}$ corresponding to the 210/211 cox2 PCR primers were excluded from sequence analysis, because potential sequence variation within PCR priming regions is masked by incorporation of synthetic primers during amplification. The nematode mtDNA genetic code (Wolstenholme et al., 1987; Okimoto et al., 1992) was used to predict amino acid sequences from the $582 \mathrm{nt}$ obtained for all taxa. Predicted polypeptide sequences were aligned using CLUSTAL V (Higgins et al., 1992); alignment of the coding nucleotide sequences was straightforward. Nuclear rDNA sequences were aligned based on secondary structure (SSU) and similarity (LSU), as described in Nadler and Hudspeth (1998). For parsimony analyses of the rDNA data and the combined datasets, inferred gaps in rDNA were recoded conservatively such that each unambiguous contiguous gap was represented as 1 character, with "nucleotide present" or "nucleotide absent" as the character states (Swofford, 1993; Crandall and Fitzpatrick, 1996). This recoding procedure yielded 44 characters for the rDNA alignment; the unrecoded gap states were treated as missing data in maximum parsimony (MP) analyses.

Trees were inferred from the mitochondrial and nuclear sequence data sets using unweighted MP (PAUP version 3.1.1). Parsimony analysis of $\operatorname{cox} 2$ data was also performed with transversion substitutions weighted 4 times transitions. The transversion weighting stepmatrix was selected by using the topologies of the 2 most-parsimonious $\operatorname{cox} 2$ trees (unweighted analysis) and a tree from neighbor-joining (log/det paralinear distances) as user trees to estimate parameters of a likelihood model using PAUP* (version 4d64). The transition : transversion ratio estimated from these 3 trees ranged from 3.41 to 3.65 (mean 3.53), which was rounded to 4 for the stepmatrix. Trees were rooted by $C$. americana; 
this choice was supported by analysis of the SSU rDNA data with additional outgroups (Nadler and Hudspeth, 1998). Combined analyses of rDNA, $\operatorname{cox} 2$, and morphological data were performed using unweighted MP. Alternative tree topologies were evaluated by parsimony criteria using the winning sites test (Prager and Wilson, 1988) and Templeton's modified test (Templeton, 1983) using PAUP*. Tree space was searched using heuristic methods (tree-bisection reconnection branchswapping, MULPARS), with 100 replicates of random stepwise addition. Reported consistency indices do not include uninformative characters. Bootstrap MP trees (2,000 replicates) were produced using heuristic searches with MULPARS option, TBR branch-swapping, and simple stepwise addition.

Substitution rate patterns for cox 2 were inferred using the combined analysis tree and the parsimony-based approximation method of Yang and Kumar (1996) as calculated in the PAMP program of the PAML package (version 1.3C; Yang, 1997). Numbers of unambiguous substitutions, as determined by parsimony, were assessed relative to trees and codon positions using MacClade (v 3.05; Maddison and Maddison, 1992). Base compositional bias was calculated according to the formula given in Thomas and Wilson (1991).

\section{Morphological data and mapping}

Morphological data (Fagerholm, 1991; Gibson, 1983) were coded as unordered states (for characters and state assignments, see Nadler and Hudspeth [1998]). MacClade was used to examine the most parsimonious distribution of character states on the tree inferred from the combined data. Developing hypotheses for morphological character evolution were limited to the tree topology inferred for the ingroup (Ascaridoidea) because many structural characters were not comparable for the outgroup, C. americana.

\section{RESULTS}

Nucleotide sequences for $\operatorname{cox} 2$ were deposited in GenBank (accession numbers AF179905-179923); alignments and tree files were deposited in TreeBase (Sanderson et al., 1994). Regions of COII protein sequence that are conserved among other organisms were also primarily conserved in these Ascaridida (Fig. 1). Twenty-nine of 37 highly conserved amino acid sites were unchanged (Fig. 1), and of the remaining 8 sites with replacements, 2 showed lack of conservation in comparisons of nematodes (Ascaridida, C. elegans, O. volvulus-amino acid sequences of the latter 2 species not shown) to other organisms (site 179 and 181; the latter also had 2 autapomorphic changes among ascaridoids). Four sites showed single autapomorphic changes (sites 103, 104, 110, 208), 1 had a synapomorphic change (site 212), and 1 (site 175 , replacement in the outgroup) was an equivocal change with respect to the combined analysis tree. The region on the N-terminal side of the aromatic sequence (Fig. 1) has an abundance of nonpolar amino acids including leucine, isoleucine, proline, valine, phenylalanine, and methionine, a characteristic of transmembrane helices in COII of other organisms.

For cox 2 codons, $69 \%$ of first positions, $84.5 \%$ of second positions, and $7.7 \%$ of third positions were constant among these Ascaridida. Frequencies of nucleotides over all 3 codon positions (Table I) showed an overrepresentation of $\mathrm{T}$ in the coding strand of species; $H$. pelagicum and $H$. reliquens were the only taxa with frequencies of $\mathrm{T}$ (averaged over all positions) less than $40 \%$. For most taxa, $\mathrm{A}+\mathrm{T}$ content was higher at third codon positions than first or second (Table I). For mean nucleotide frequencies over all taxa, values of base-compositional bias were 0.078 (all positions), 0.031 (first positions), 0.045 (second positions), 0.231 (third positions), and 0.485 (4-fold degenerate sites). Substitution rate matrices ( $Q$ matrices) for cox2 revealed a bias to $\mathrm{T}$, with the greatest bias for the transition substitution $\mathrm{C}$ to $\mathrm{T}$ (Table II). For all 3 codon positions and 4fold degenerate sites, rates of substitution from nucleotides $\mathrm{C}$, $\mathrm{A}$, or $\mathrm{G}$ to $\mathrm{T}$ were always greater than the corresponding reverse substitution. This pattern was most pronounced for 4-fold degenerate sites. For the combined evidence tree, parsimony changes by codon position or type of site included (unambiguous changes/total length): first positions (96/138), second positions (32/49), third positions (456/719), 4-fold degenerate sites (121/180). Thus, ratios of substitution at first: second :third positions of codons were $3: 1: 14.3$ (unambiguous substitutions) and 2.8:1:14.7 (total tree length).

Previously published results (Nadler and Hudspeth, 1998) revealed that parsimony analysis of the rDNA data $(2,557 \mathrm{nt}$ characters, 44 recoded gap characters, 173 parsimony informative sites) yielded 3 trees of equal length with consistency indices of 0.54 that are summarized by strict consensus (Fig. 2). The Anisakinae, Ascaridinae, Contracaecinae, and Raphidascarididae (sensu Fagerholm, 1991) were supported strongly ( $\geq 99 \%$ ) in bootstrap parsimony analysis of these rDNA data (Fig. 2).

Equal-weighted parsimony analysis of the cox2 nucleotide data (582 nt characters) yielded 2 trees (length 886, consistency index $[\mathrm{CI}] 0.40,201$ parsimony informative sites). The strict consensus of these trees (Fig. 3) contains polytomies representing conflict between the trees, as each was fully dichotomous. This cox 2 strict consensus tree has considerably less structure than the strict consensus of rDNA trees, and bootstrap MP analysis of the cox 2 data set indicated poor support for many groups (Fig. 3). Transversion-weighted parsimony analysis of the cox 2 nucleotide data yielded 1 fully dichotomous tree (Fig. 4) with much greater resolution than the consensus tree for equal-weighting; however, transversion-weighted bootstrap MP analysis also revealed poor support for many clades (data not shown).

The combined analysis of all molecular plus morphological characters $(3,159$ characters, 517 parsimony informative characters) yielded 1 most parsimonious tree (Fig. 5, length 1,866, CI 0.47). Except for the relationship of T. canis, the topology of this tree was consistent with Fagerholm's (1991) classification. Bootstrap resampling and MP analysis showed strong support for some clades and moderate support for other groups (Fig. 5).

The evolution of morphological, life history, and COII amino acid characters were explored relative to the combined evidence tree (Figs. 1, 5). The range of consistency indices for structural and life history characters (Table III) showed that some of these characters were explained by the minimum number of required changes, whereas others were inferred to be highly homoplastic.

Alternative tree topologies depicting certain traditional expectations were compared to the combined evidence tree using statistical tests. These alternative topologies (Table IV) included restoring monophyly to the Ascarididae and Toxocarinae, restoring a monophyletic Hysterothylacium with an Iheringascaris sister group, depicting $G$. pelagia as a member of the Anisakidae, and the most parsimonious alternative topology for Parascaris within the Ascaridinae, i.e., not depicting Parascaris as the sister-taxon of Ascaris. 
Anisakis $\mathrm{Cl} 1$

Anisakis cl 4

Ps. decipiens

Te. caballeroi

Co. multipapillatum

To. canis

As. lumbricoides

As. suum

$P a$. equorum

$B$ a. procyonis

$B a$. transfuga

$T x$. leonina

Po. depressum

Go. pelagia

Hy. pelagicum

Hy. reliquens

Ih. inquies

Hy. fortalezae

He. tunicatus

Cr. americana $\begin{array}{lllll}26 & 36 & 46 & 56 & 66\end{array}$

NFYCSLLFGV LSFVSVMFGY LLFSNFYFKS KKIEYQFGEL LCSIFPTLIL NFNCSLLFGV LSFVSVMFGY LLFSNFYFKS KKIEYQFGEL LCSIFPTLIL NFNCSLLFGV LSFVSVMFVY LLFSSFYFKS KKIEYQLGEL LCSIFPTSIL NFNCSLLFGV LSFVSAMFFY LLFSKFYFKS KKVEYQLGEL LCSIFPTLIL NFNCSLLFGV LSFVTVMFFY LLLSRFYFKS KKIEYQFGEL LCSVFPTLIL NFNCSLLFGV LSFVST NFNCSLLFGV LSFVSTMFVY LLLSSFYFKS KKIEYQFGEL LCSVFPTLIL NFNCSLLFGV LSFVSTMFVY LLLSSFYFKS KKIEYQFGEL LCSVFPTLIL NFNCSLLFGV LSFVSTMFVY LLLSNFYFKS KKIEYQFGEL LCSVFPTLIL NFNCSLLFGV LSFVSTMFIY LLLSRFYFKS KKVEYQFGEL LCSVFPTLIL NFNCSLLFGV LSFVSTMFIY LLLSRFYFKS KKVEYQFGEL LCSVFPTLIL NFNCSLLFGV LP्PVSTMFVY LLLSCGFYFKS KKVEYQFGEL LCSVFPTLIL NFNCSLLFGI LAFVCTMFIY LLLNSFYFKS KKIEYQFGEL LCSVFPTLIL NFNCSLLFGV LSFVSAVFAY LLLSHFYFKS KKIEYQFGKL LCSVFPTLIL NFNCKLLFGV LSFVSTVFAY LMLSHFYFKS KKIEYQFGEL LCSVFPTLIL NFNCSLLFGV LSFVSTVFAY LMLSHFYFKS KKIEYQFGEL LCSVFPTLIL NFNCSLLFGV LSFVSTVFAY LLLSHFYFKS KKIEYQFGEL LCSVFPTLIL NFNCSLLFGV LSFVCTLFVY LLLSHFYFKS KKIEYQFGEL LCSVFPTLIL NFNCSLLFGV LVFVSTMFVY LLLSSYYYFKS KKIEYQLGEL LCSVFPTLIL NFNCSLLFGV LAFVSTMFIF LIFNRFYFKS KKIEYQFGEL LCSVFPTLIL

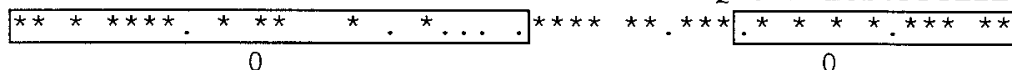

$\begin{array}{lllll}76 & 86 & 96 & 106 & 116\end{array}$

VAQMVPSLSL LYYYGLMNLD SNLTVKVTGH OWYWSYEFSD IPGLEFDSYM VAOMVPSLSL LYYYGLMNLD SNLTVKVTGH OWYWSYEFGD IPGLEFDSYM VAQMVPSLSL LYYYGLMNLD SNLTVKVTGH OWYWSYEFSD IPGLEFDSYM VAQMIPSLSL LYYYGLMNLD SNLTVKVTGH OWYWSYEFSD IPGLEFDSYM VMOMIPSLSL LYYYGLMNLD SSLTIKVTGH OWYWSYEFSD IPGLEFDSYM VMOMVPSLSL LYYYGLMIND SNLTVKVTGH OWYWSYEFSD IPGLEFDSYM VMQMVPSLSL LYYYGLMNLD SSLTVKVTGH OWYWSYEFSD IPGLEFDSYM VMOMVPSLSL LYYYGLMNLD SSLTVKVTGH OWYWSYEFSD IPGLEFDSYM VMQMVPSLSL LYYYGLMNLD SNLTVKVTGH OWYWSYEFSD IPGLEFDSYM VMOMVPSLSL LYYYGLMNLD SSLTVKVTGH OWYWSYEFSD IPGLEFDSYM VMOMVPSLSL LYYYGLMNLD SSLTVKVTGH OWWWSYEFSD IPGLEFDSYM VMOMVPSLSL LYYYGLMNLD SSLTIKVTGH OWYWSYEFSD VPGLEFDSYM VIQMVPSLSL LYYYGLMNLD SSLTVKVTGH OWYWSYEFSD IPGLEFDSYM VMOMIPSLSL LYYYGLMNLD SNLTIKVTGH OWYWTYEFSD IPGLEFDSYM VMOMIPSLSL LYYYGLMNLD SNLTVKVTGH OWYWSYEFSD IPGLEFDSYM VMQMIPSLSL LYYYGLMNLD SNLTIKVTGH OWYWSYEFSD IPGLEFDSYM VMQMIPSLSL LYYYGLMNLD SNLTVKVTGH OWYWSYEFSD IPGLEFDSYM VIQMVPSLSL LYYYGLMNLD SSLTIKVTVH QWYWSYEFSD IPGLVEDSYM VMQMVPSLSL LYYYGLMNLD SSLTVKVIGH OWYWSYEFSD IPGLEFDSYM VMOTIPSLSL LYYYGLMNLD SNLTVKVTGH OWYWSYEFSD IPGLEFDSYM

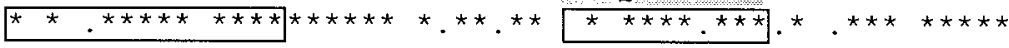

FIGURE 1. Alignment of COII sequences. Amino acids are numbered according to the complete protein of Ascaris suum. Invariant sites among these taxa are marked with an asterisk; sites with chemically conserved amino acid replacements are marked with a period. Sequence regions with high levels of amino acid conservation, as inferred from comparisons of other organisms, are shaded. The combined evidence tree (Fig. 5) was used to infer unambiguously autapomorphic (underlined) and shared-derived (bold) amino acid replacements. Conserved elements of COII include the membrane-spanning domains (boxes marked 0), aromatic sequence (box 1), negatively charged cytochrome $c$ binding residue (box 2), $\mathrm{Cu}_{\mathrm{A}}$ binding histidine residue (box 3), $\mathrm{Cu}_{\mathrm{A}}$ binding cysteine residue (box 4), negatively charged cytochrome $c$ binding residue (box 5), and $\mathrm{Cu}_{\mathrm{A}}$ binding histidine residue (box 6). 
Anisakis cl 1

Anisakis cl 4

Ps. decipiens

Te. caballeroi

Co. multipapillatum

To. canis

As. lumbricoides

As. suum

Pa. equorum

Ba. procyonis

$B a$. transfuga

$T x$. leonina

Po. depressum

Go. pelagia

Hy. pelagicum

Hy. reliquens

Ih. inquies

Hy. fortalezae

He. tunicatus

Cr. americana
$126 \quad 136 \quad 146 \quad 156 \quad 166$

KSVDQLELGE PRILEVDNRC VVPCDINVRF CITSGDVIHS WALPSMSIKI. KSVDQLELGE PRILLEDNRC VVPCDINVRF CITSGDVIHS WALPSMSIKL. KSVDQLELGE PRLLEVDNRC VVPCDTNIRF CITSGDVIHS WALPSMSIKL KSIDQLLPGE PRLLEVDNRC VVPCDINVRF CITSGDVIHS WALPSMSIKL KSLDQLELGE PRLLEVDNRC VIPCDTNIRF CITSGDVTHS WALPSLSIKL. KSLDQLELGE PRLLEVDNRC VVPCDTNIRF CITSGDVIHS WALPSMAIKL KSLDQLELGE PRILEVDNRC VVPCDVNIRF CITSGDVIHS WALPSMSIKI KSLDQLELGE PRLLEVDNRC VVPCDVNIRF CITSGDVIHS WALPSMSIKI KSLDQLELGE PRLLEVDNRC VVPCDVNIRF CITSGDVIHS WALPSMSIRI KSLDQLELGE PRELEVDNRC VVPCDVNIRF CITSGDVIHS WALPSMSIRI KSLDQLELGE PRELEVDNRC VVPCDVNVRF CITSGDVIHS WALPSMSIKL KSLDQLELGE PRILEVDNRC VVPCDVNVRF CITSGDVIHS WALPSMSIRI KSLDQLELGE PRLLEVDNRC VVPCDTNIRF CITSSPVVIHS WALPSMSIKI KSVDQLALGE PRLLEVDNRC VVPCDTNIRF CITSGDVIHS WALPSMSIKL KSVDQLELGE PRILEVDNRC VVPCDTNIRF CITSGDVIHS WALPSMAIKI. KSVDQLELGE PRILEVDNRC VIPVDANIRF CITSGDVIHS WALPSMAIKI KSLDQLELGE PRILEVDNRC VIPCDTNIRF CITSGDVIHS WALPSMAIKL KSLDQLELGE PRILEVDNRC VVPCDINVRF CITSGDVTHS WALPSMSIKL KSLDQLNLGE PRILEVDNRC VVPCNTNIRF CITSADVIHS WALPSMAIRL KSLDQLNLGE PRILEVDNRC VVPCETNIRF CVTSADVIHS WALPTMSIKV

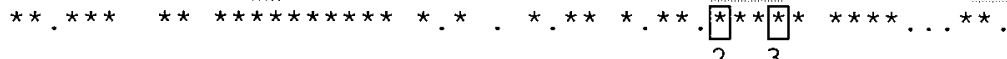

$\begin{array}{llll}176 & 186 & 196 & 206\end{array}$

DAMSGILSTV SYSFPTVGVF YGQCSEICGA NHSFMPIALEVTLL DAMSGILSTV SYSFPTVGVF YGQCSEICGA NHSFMPIALEVTLL DAMSGILSTL SYSFPTVGVF YGQCSEICGA NHSFMPIALEVTLL DAMSGILSTL SYSFPVLGVF YGOCSEICGA NHSFMPISLLEILLL DAMSGILSTL SYSFPVVGVF YGQCSEICGA NHSFMPIALEVTLM DAMSGILTTL SYSFPVVGVF YGQCSEICGA NHSFMPIVLEVTLI DAMSGTLSTL SYSFPVVGVF YGQCSEICGA NHSFMPVALEVTLL DAMSGTLSTL SYSFPVVGVF YGOCSEICGA NHSFMPVALEVTLL DAMSGILSTL SYSFPVVGVF YGQCSEICGA NHSFMPVALEVTLL DAMSGILSTL SYSFPVVGVF YGQCSEICGA NHSFMPVALEVTLL DAMSGILSTL SYSFPVVGVF YGQCSETCGA NHSFMPVALEVTLL DAMSGILSTL SYSFPVIGVF YGQCSEICGA NHSFMPIALEVTLL DAMSGILTTL SYSFPLVGVF YGQCSEICGA NHSFMPIALEVTLL DAMSGILSTL SYSFPVVGVF YGQCSEICGA NHSFMPIALEVTLL DAMSGMLSTL SYSFPVVGVF YGQCSETCGA NHSFMPIALEVTLL BAMSGILSTL SYSFPVIGVF YGQCSEICGA NHSFMPIALEVTLL DAMSGILSTL SYSFPVVGVF YGQCSEICGA NHSFMPIALEVTLL DAMSGILSTL SYSFPVIGVF YGQCSETCGA NHNFMPTALEVTLL DAMSGVLTTL SYNFPVVGVF YGQCSEICGA NHSFMPIALEVTLL DAMSGILNTL SYSFPVIGVF YGQCSEICGA NHSFMPIALEVTLL

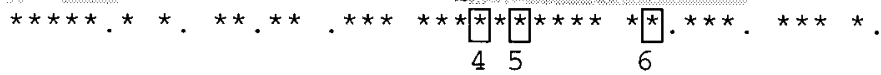

FIGURE 1. Continued.

\section{DISCUSSION}

\section{Sequence comparisons}

The amino terminus of these COII proteins contains many hydrophobic amino acids, consistent with the location of transmembrane helix anchors in COII proteins of other organisms (Bisson et al., 1982), including nematodes (Thomas and Wilson,
1991). The transmembrane helices show the highest amount of amino acid variation among these ascaridoids (Fig. 1); however, this observation is expected because many conservative amino acid replacements in the transmembrane region of COII appear to be selectively neutral as inferred from comparative analysis of other organisms (Templeton, 1996). The aromatic sequence region, GxQWYWxYEY (where x's designate sites without ap- 
TABLE I. Nucleotide frequencies of $\operatorname{cox} 2$ sequences by taxon and position.

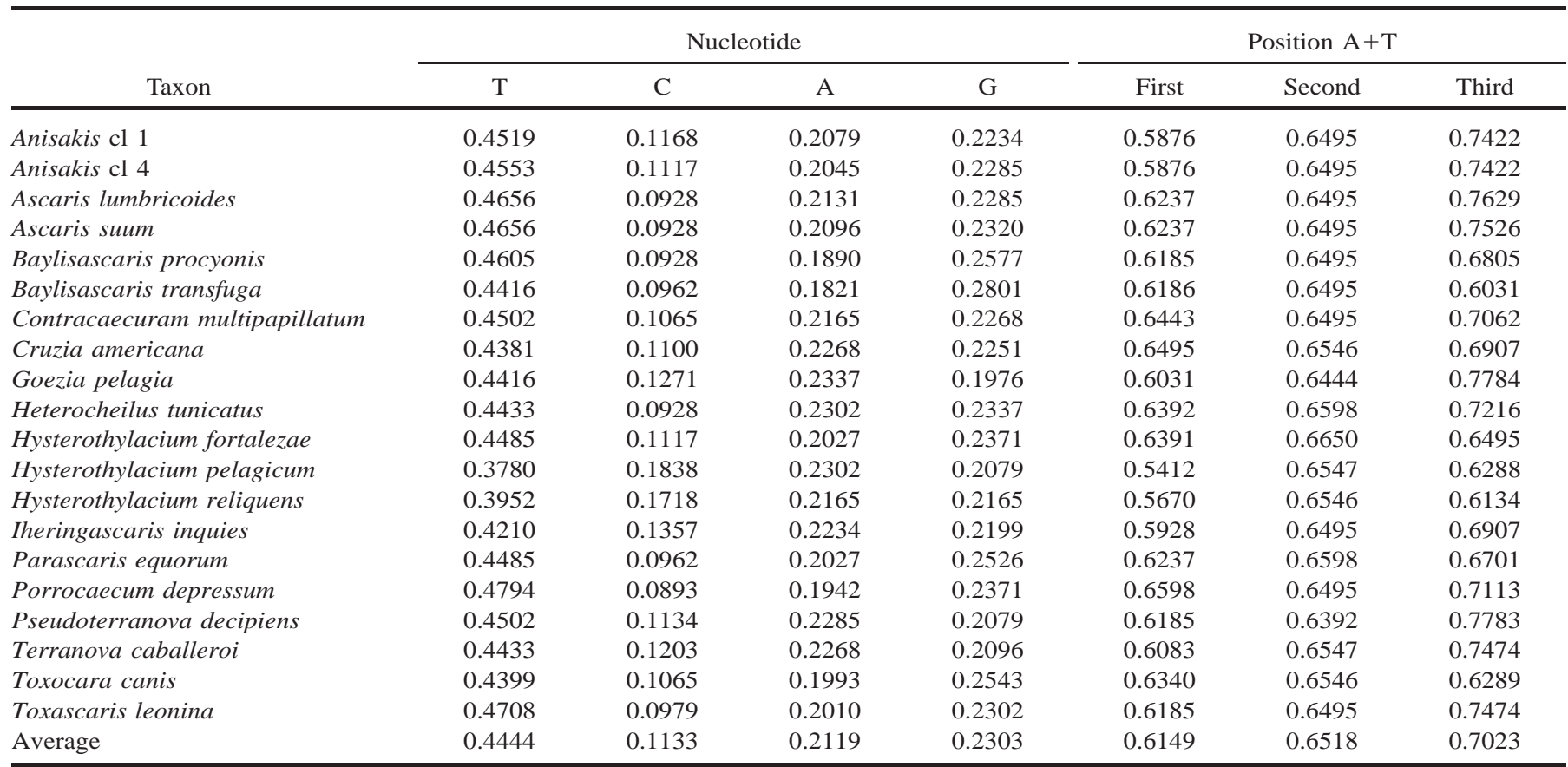

TABLE II. Rate matrix estimate of the pattern of nucleotide substitution for cox 2 based on parsimony and the combined evidence tree.

\begin{tabular}{|c|c|c|c|c|}
\hline \multirow[b]{2}{*}{ From } & \multicolumn{4}{|c|}{ To } \\
\hline & $\mathrm{T}$ & $\mathrm{C}$ & A & G \\
\hline \multicolumn{5}{|c|}{ All positions } \\
\hline $\mathrm{T}$ & -0.667416 & 0.293187 & 0.126929 & 0.247300 \\
\hline $\mathrm{C}$ & 1.319390 & -1.472471 & 0.063034 & 0.090047 \\
\hline A & 0.294809 & 0.032533 & -1.203737 & 0.876395 \\
\hline G & 0.489936 & 0.039642 & 0.747536 & -1.277113 \\
\hline \multicolumn{5}{|c|}{ First positions } \\
\hline $\mathrm{T}$ & -0.892312 & 0.642053 & 0.083447 & 0.166811 \\
\hline $\mathrm{C}$ & 1.792079 & -1.960081 & 0.142793 & 0.025209 \\
\hline $\mathrm{A}$ & 0.109765 & 0.067294 & -0.787650 & 0.610591 \\
\hline G & 0.233341 & 0.012634 & 0.649327 & -0.895302 \\
\hline \multicolumn{5}{|c|}{ Second positions } \\
\hline $\mathrm{T}$ & -0.615646 & 0.411544 & 0.102190 & 0.101912 \\
\hline $\mathrm{C}$ & 1.042744 & -1.693887 & 0.128755 & 0.522388 \\
\hline A & 0.160663 & 0.079893 & -0.847132 & 0.606576 \\
\hline G & 0.209621 & 0.424073 & 0.793576 & -1.427270 \\
\hline \multicolumn{5}{|c|}{ Third positions } \\
\hline $\mathrm{T}$ & -0.476605 & 0.208100 & 0.098435 & 0.170070 \\
\hline $\mathrm{C}$ & 5.178309 & -5.541286 & 0.155168 & 0.207809 \\
\hline $\mathrm{A}$ & 0.811710 & 0.051421 & -3.252610 & 2.389479 \\
\hline G & 0.424680 & 0.020854 & 0.723578 & -1.169112 \\
\hline \multicolumn{5}{|c|}{ 4-fold degenerate sites } \\
\hline $\mathrm{T}$ & -0.503096 & 0.147581 & 0.123087 & 0.232429 \\
\hline $\mathrm{C}$ & 6.291296 & -7.302287 & 0.448629 & 0.562362 \\
\hline A & 2.968347 & 0.253793 & -4.405633 & 1.183493 \\
\hline G & 2.676191 & 0.151891 & 0.565054 & -3.393135 \\
\hline
\end{tabular}

parent amino acid conservation), is normally highly conserved, presumably because it mediates electron transfer from subunit II to heme $a$ of subunit I (Müller et al., 1988; Overholtzer et al., 1996). In these ascaridoids, the aromatic region is represented by the consensus sequence GHQWYWSYEF (positions 104-113), where each of the underlined amino acids had a replacement in 1 ascaridoid. The position 104 replacement (valine) in $H$. fortalezae was unexpected based on conservation in other organisms; however, functional studies in yeast show that replacements of the conserved glycine with other small uncharged residues (such as valine) does not compromise subunit II function (Overholtzer et al., 1996). The conservative replacement at position 113 in the aromatic sequence (phenylalanine for tyrosine) was found in all Ascaridida; in C. elegans and $O$. volvulus the tyrosine is conserved (Okimoto et al., 1992; Keddie et al., 1998). Another highly conserved region in other organisms is the DV(hydrophobic amino acid)H sequence (Müller et al., 1988); ascaridoids have retained the aspartic acid (D) at position 161 (providing a negative charge for cytochrome $c$ binding), followed by the invariant valine, an isoleucine, and the invariant histidine, which is 1 of 2 involved in copper A $\left(\mathrm{Cu}_{\mathrm{A}}\right)$ binding. Subunit II sequences also typically have a conserved PGR sequence at positions 179-181. Nematodes sequenced to date have the glycine, but the other 2 residues are characterized by nonconservative replacements. The Ascaridida and C. elegans (Okimoto et al., 1992) have the sequence SG (hydrophobic amino acid), whereas $O$. volvulus has NGI (Keddie et al., 1998). A region near the C-terminus of COII proteins contains the other critical ligands to $\mathrm{Cu}_{\mathrm{A}}$ and a second charged amino acid involved in cytochrome $c$ binding. The consensus sequence for this region, CSE(hydrophobic amino acid) CGxxHxxxPI, is found in the Ascaridida (positions 199-212) with the exception of the final isoleucine, which in Ascaris, 


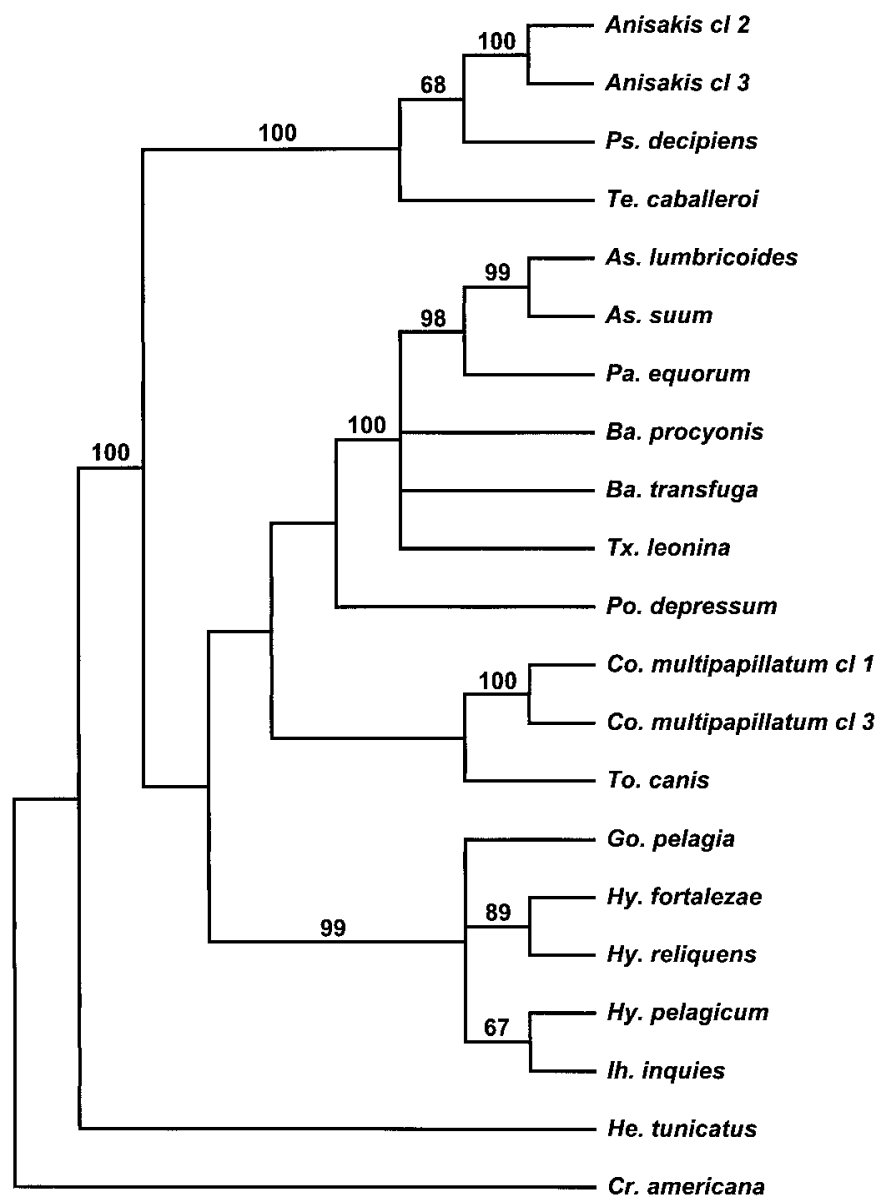

FIGURE 2. Strict consensus of 3 equally parsimonious trees inferred from unweighted analysis of rDNA sequence data (2,557 characters, 173 parsimony-informative sites, 1,047 steps, CI 0.538). Results from bootstrap resampling and MP inference are also shown relative to the strict consensus tree for clades receiving $>65 \%$ bootstrap support. The bootstrap 50\% majority-rule consensus tree differed from the topology shown in that $T$. leonina was resolved as the "basal" lineage within the Ascaridinae, and (C. multipapillatum $\mathrm{cl} \mathrm{1,} \mathrm{C.} \mathrm{multipapillatum} \mathrm{cl} 2$ ) and T. canis were each depicted as polytomies within the clade that includes taxa representing the Ascarididae and Raphidascarididae.

Parascaris, and Baylisascaris is replaced by another hydrophobic amino acid (valine).

These amino acid sequences for ascaridoids show conservation of the most critical functional residues characteristic of COII in other organisms (Holm et al., 1987). Subunit II of cytochrome oxidase is a key component of electron transfer during aerobic respiration, and given the observed conservation among ascaridoids, it seems possible that the aerobic larval component of the aerobic/anaerobic metabolism of A. suum (Komuniecki and Komuniecki, 1995) may also be present in other members of the superfamily, including species developing in aquatic environments.

Like other nematode mtDNA sequences (Thomas and Wilson, 1991; Okimoto et al., 1992; Hyman and Azevedo, 1996; Hugall et al., 1997; Blouin et al., 1998; Keddie et al., 1998), $\operatorname{cox} 2$ is extremely $\mathrm{A}+\mathrm{T}$ rich in ascaridoids. The value for thirdposition base compositional bias of ascaridoid cox2 is the same as for Caenorhabditis species (Thomas and Wilson, 1991),

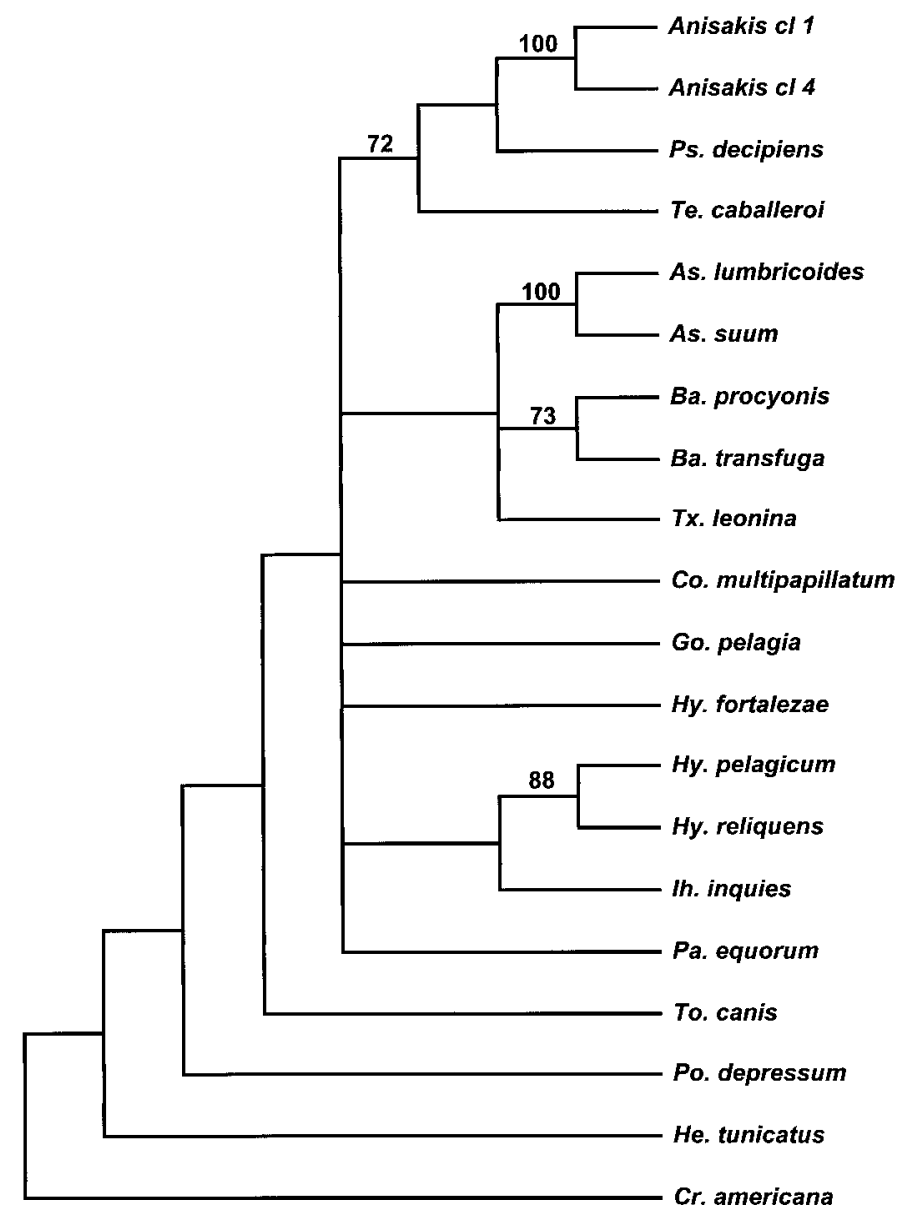

FIGURE 3. Strict consensus of 2 equally parsimonious trees inferred from unweighted analysis of cox 2 nucleotide data (582 characters, 201 parsimony-informative sites, 886 steps, CI 0.40). Results from bootstrap resampling and MP inference are also shown relative to the strict consensus tree; percentages of clades $(>65 \%)$ are shown above internal nodes. The bootstrap $50 \%$ majority-rule consensus tree had less resolution than the strict consensus shown and is defined by the topology: (C. americana, (H. tunicatus, (P. depressum, (T. canis, (() Anisakis $\mathrm{cl}$ 1, Anisakis $\mathrm{cl} 4), P$. decipiens $), T$. caballeroi $),((H$. pelagicum, H. reliquens), I. inquies), H. fortalezae, G. pelagia, P. equorum, C. multipapillatum, ((B. procyonis, B. transfuga), T. leonina, (A. lumbricoides, A. suum))))))).

which is only slightly less biased than Drosophila yakuba (Clary and Wolstenholme, 1985). Averaged over all taxa, basecompositional bias of ascaridoid cox 2 was 10 -fold greater at 4fold degenerate sites than for first or second codon positions. Rate matrix analysis (Table II) reveals a strong pattern of substitutional bias to thymine at all codon positions; this bias was most pronounced at 4-fold degenerate sites, which represent sites most likely to be selectively neutral within protein coding genes (Wolfe et al., 1989). This pattern and the observed A+T bias is consistent with A+T pressure (Jukes and Bhushan, 1986; Jermiin et al., 1995), a pattern of nonrandom substitution resulting in the accumulation of $\mathrm{A}+\mathrm{T}$ nucleotides in protein-coding genes, particularly at synonymous sites. For ascaridoid $\operatorname{cox} 2$, differential patterns of compositional and substitutional bias by codon position are consistent with an underlying mutational bias (Sueoka, 1992) that has been previously suggested for nematode mtDNA (Thomas and Wilson, 1991; Okimoto et 


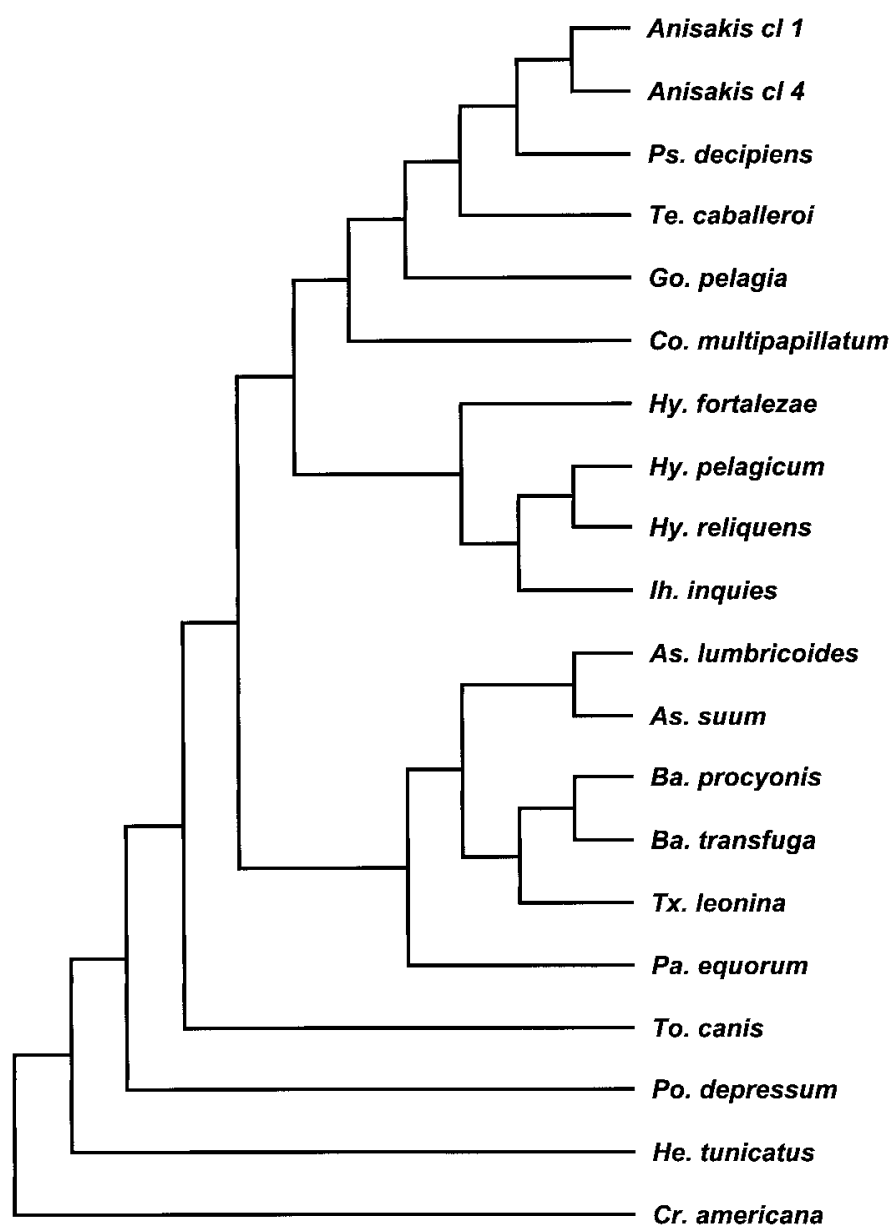

FIgURE 4. Parsimony tree for cox2 nucleotide data (1,859 steps), inferred using a transversion-weighted stepmatrix.

al., 1992; Hyman and Azevedo, 1996; Hugall et al., 1997; Blouin et al., 1998). Due to a relatively rapid rate of change, compositional bias, and tendency for multiple hits (Thomas and Wilson, 1991; Blouin et al., 1998), it has been suggested that nematode mtDNA is likely to be of less phylogenetic utility than many nuclear genes (Blouin et al., 1998). The comparatively poor resolution and higher homoplasy of the cox 2 gene tree in comparison to rDNA (Nadler and Hudspeth, 1998) for the same set of taxa is consistent with this suggestion, and it is noteworthy that $\operatorname{cox} 2$ is among the more conservatively evolving mtDNA genes.

\section{Phylogenetic hypotheses}

Previous analyses of SSU and LSU rDNA sequences (Nadler, 1992; Nadler and Hudspeth, 1998) showed that rDNA is informative for inferring ascaridoid phylogeny. Yet, statistical comparison of alternative trees and results from bootstrap resampling also revealed that these rDNA sequences did not provide an entirely robust hypothesis. In an attempt to improve upon this phylogenetic estimate, sequence data were obtained from another locus ( $\operatorname{cox} 2)$, and all available nucleotide sequence and morphological data were combined for parsimony analysis. This approach to phylogenetic analysis, typically referred to as combined or total evidence (Eernisse and Kluge, 1993; Kluge,

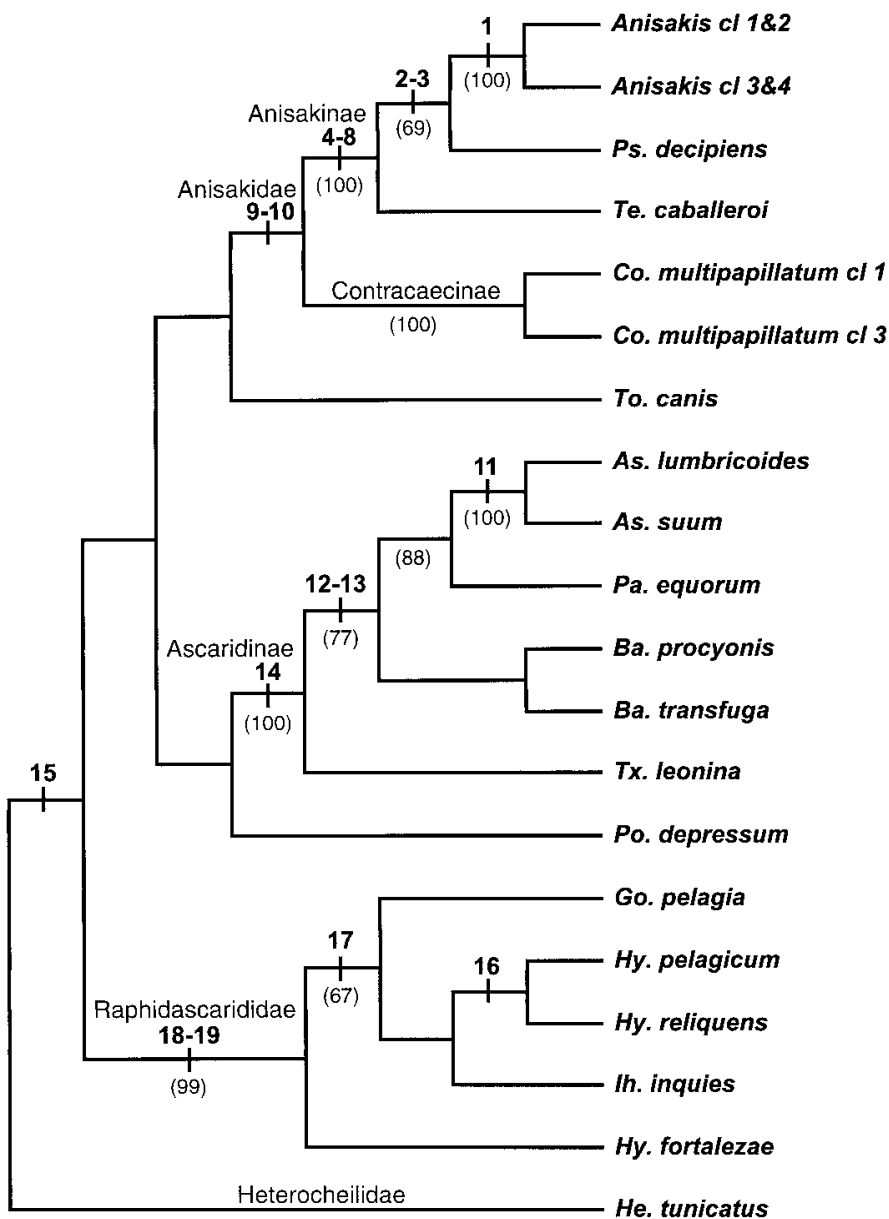

FIGURE 5. Maximum parsimony tree inferred from combined analysis of all molecular and morphological data (3,159 characters, 517 parsimony informative, 1,866 steps, CI 0.47 ). Inferred synapomorphic changes in morphological and amino acid characters with respect to the combined evidence tree are labeled: 1, AA $185 \mathrm{Val}$; 2, AA $191 \mathrm{Thr}$; 3 , distal papillae proximal; 4, AA 69 Ile; 5, AA 77 Ala; 6, caudal plates present; 7, ventriculus long; 8, lips reduced; 9, left-glandular excretory system; 10 , excretory pore between lips; 11 , proximal papillae grouped posterior; 12, AA 212 Val; 13, distal papillae united; 14, ventriculus absent; 15, gubernaculum absent; 16, AA 47 Met; 17, AA 44 Ala; 18, AA 50 His; 19, left-filamental excretory system. Results from bootstrap resampling and MP inference are shown relative to the single most parsimonious tree; percentages of clades $(>60 \%)$ are shown below internal nodes. The topology of the bootstrap $50 \%$ majority-rule consensus tree showed less resolution and is defined by the topology: $(H$. tunicatus, ((( Anisakis cl 2, Anisakis $\mathrm{cl} 3), P$. decipiens $),$ T. caballeroi $)$, ( (( $(H$. pelagicum, H. reliquens $), I$. inquies, G. pelagia $), H$. fortalezae $)$, (C. multipapillatum $\mathrm{cl} 1, C$. multipapillatum $\mathrm{cl} 3$ ), P. depressum, T. canis, (T. leonina, ((B. procyonis, B. transfuga), (P. equorum, (A. lumbricoides, A. suum))))))).

1998), has been advocated as the method of choice to provide the best estimate of evolutionary history by maximizing the explanatory power of the available data. A practical advantage of this approach is that it is efficient for large data sets. In addition, parsimony is the only method conducive to combining disparate types of data, such as nucleotide sequences and morphology, in a single analysis.

Parsimony analysis of the combined data yielded a single tree (Fig. 5) that has greater congruence with Fagerholm's (1991) classification than the individual gene trees inferred from rDNA 
TABLE III. Mapping of structural and life history characters on the combined evidence tree.

\begin{tabular}{lccc}
\hline \multicolumn{1}{c}{ Character } & States* & Steps & CI \\
\hline 1. Median papilla & 2 & 3 & 0.33 \\
2. Paracloacal papillae & 2 & 4 & 0.25 \\
3. Distal papillae number & 2 & 1 & 1.00 \\
4. Distal papillae type & 4 & 3 & 1.00 \\
5. Proximal papillae type & 3 & 2 & 1.00 \\
6. Spicules & 2 & 2 & 0.50 \\
7. Gubernaculum & 2 & 1 & 1.00 \\
8. Caudal plates & 2 & 1 & 1.00 \\
9. Caudal alae & 2 & 2 & 0.50 \\
10. Ventriculus & 3 & 2 & 1.00 \\
11. Intestinal cecum & 2 & 3 & 0.33 \\
12. Lips & 2 & 1 & 1.00 \\
13. Lip denticles & 2 & 2 & 0.50 \\
14. Interlabia & 2 & 6 & 0.17 \\
15. Excretory pore & 3 & 2 & 1.00 \\
16. Excretory system & 3 & 2 & 1.00 \\
17. Cervical alae & 3 & 6 & 0.33 \\
18. Eggshell & 2 & 2 & 0.50 \\
19. Ventricular appendix & 2 & 2 & 0.50 \\
20. Proximal papillae pairs & 3 & 3 & 0.67 \\
21. Definitive host & 4 & 4 & 0.75 \\
22. Life history & 2 & 2 & 0.50 \\
\hline
\end{tabular}

* 1, Single/joined; 2, separate/joined double; 3, 2 pair/4 pair; 4, distal united/distal unjoined/proximal/subventral rows; 5 , straight rows/grouped anterior/grouped posterior; 6 , alate/rod; 7, present/absent; 8 , present/absent; 9, present/absent; 10, short/long/absent; 11, present/absent; 12, prominent/reduced; 13, present/ absent; 14, present/absent; 15, between nerve ring and lips/near nerve ring/ between lips; 16, left-right filamental/left glandular/left-filamental; 17, present/absent; 18 , thick-walled/thin-walled; 19 , present/absent; $20,<6$ pairs/650 pairs/>50 pairs; $21, \mathrm{mammal} /$ fish/bird/reptile; 22 , terrestrial/aquatic.

or cox2 (Figs. 2-4). Nevertheless, certain clades in this tree remain weakly supported as assessed by bootstrap resampling, and statistical comparisons show that some alternative topologies representing traditional expectations are not worse. Although the combined evidence tree does not encompass the full diversity of the Ascaridoidea ( $>50$ described genera), this phylogenetic hypothesis suggests that Fagerholm's (1991) taxonomic summary represents a reasonable working classification that can be examined in greater detail as more taxa are included in phylogenetic analysis. One disagreement between the com- bined evidence tree and all modern classifications concerns $T$. canis that was depicted as the most basal branch of the anisakids. Classically, Toxocara and Porrocaecum have been retained as a distinct subfamily (Toxocarinae) within the Ascarididae because they possess a ventriculus and have a terrestrial life cycle (Gibson, 1983; Fagerholm, 1991). Clearly, the former character cannot be considered informative for inferring group membership because the presence of a ventriculus is the plesiomorphic condition as inferred from the combined evidence. Nevertheless, restoring monophyly to the Ascarididae and Toxocarinae such that the latter subfamily is the sister group to the Ascaridinae requires only 6 additional steps by parsimony, which was not significantly worse. Thus, from a statistical perspective, these data are insufficient to discriminate between the representation in Figure 5 and the traditional alternative hypothesis for the Toxocarinae.

In the combined evidence tree, species of Hysterothylacium were not monophyletic. This finding was also obtained for analyses of rDNA and combined analysis of rDNA and morphology (Nadler and Hudspeth, 1998) and herein for transversionweighted analysis of cox2. Analysis of alternative trees for rDNA showed that a monophyletic Hysterothylacium with an Iheringascaris sister group was not significantly worse (Nadler and Hudspeth, 1998). However, with the combined evidence, restoring a monophyletic Hysterothylacium (()Hysterothylacium spp.), Iheringascaris), Goezia) required a minimum of 23 additional steps, and was significantly worse. In contrast, the topology $((((H$. pelagicum, $H$. reliquens $), I$. inquies $), H$. fortalezae), G. pelagia) required 6 additional steps and was not significantly worse. Deardorff and Overstreet (1980) proposed resurrecting Iheringascaris (formerly Thynnascaris inquies, a genus previously used for several other species of Hysterothylacium) because $I$. inquies has conspicuous annulations and additional caudal papillar rows when compared to Hysterothylacium species. The combined evidence tree (Fig. 5) does not provide a topological basis for this generic distinction, and comparison of alternative topologies also suggests that Iheringascaris is best represented as more closely related to some Hysterothylacium, than as a sister taxon to a monophyletic Hysterothylacium.

The Anisakidae as typically constituted (Anisakinae plus Contracaecinae) was recovered by maximum likelihood analy-

TABLE IV. Alternative trees compared using statistical tests and the combined data.

\begin{tabular}{|c|c|c|c|}
\hline Tree topology* & Length & $\begin{array}{c}P^{\dagger} \text { Templeton's } \\
\text { test }\end{array}$ & $\begin{array}{c}P^{\dagger} \text { winning } \\
\text { sites }\end{array}$ \\
\hline MP tree (Fig. 5): $(20,(((((11,12), 13), 9), 10),((((((1,2), 16), 17),(7,8)), 18),(15,(19,((5,6),(14,(3,4))))))))$ & 1,866 & & \\
\hline$(20,((((11,12), 10), 13), 9),((((((1,2), 16), 17),(7,8)), 18),(15,(19,((5,6),(14,(3,4))))))))$ & 1,889 & $<0.005$ & 0.001 \\
\hline Alt tree 3: $\quad(20,(((((11,12), 13), 10), 9),((((((1,2), 16), 17),(7,8)), 18),(15,(19,((5,6),(14,(3,4))))))))$ & 1,872 & 0.30 & 0.33 \\
\hline Alt tree 4: $\quad(20,((((11,12), 13), 10),(((((((1,2), 16), 17), 9),(7,8)), 18),(15,(19,((5,6),(14,(3,4))))))))$ & 1,911 & $<0.001$ & $<0.001$ \\
\hline
\end{tabular}

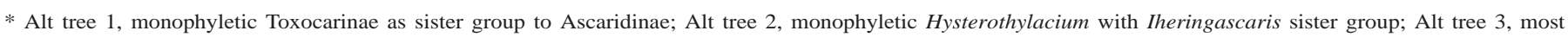
parsimonious Hysterothylacium + Iheringascaris clade with Goezia sister group; Alt tree 4, most parsimonious topology with Goezia within the Anisakidae; Alt tree 5, most parsimonious topology excluding a Parascaris-Ascaris clade. Parenthetical tree descriptions written as rooted, although tests do not require rooted trees. Key to taxa: 1, Anisakis cl 2; 2, Anisakis cl 3; 3, A. lumbricoides; 4, A. suum; 5, B. procyonis; 6, B. transfuga; 7, C. multipapillatum cl 1; 8, C. multipapillatum cl 3; 9, G. pelagia; 10, H. fortalezae; 11, H. pelagicum; 12, H. reliquens; 13 , I. inquies; 14, P. equorum; 15, P. depressum; 16, P. decipiens; 17, T. caballeroi; 18, T. canis; 19, T. leonina; 20, H. tunicatus.

† Probability of obtaining a more extreme test statistic under the null hypothesis of no difference between the two trees (2-tailed). 
sis of rDNA (Nadler and Hudspeth, 1998) and in the combined evidence tree. However, for the combined evidence, this clade was not recovered in bootstrap MP analysis. In some other estimates of gene trees (MP rDNA, equal-weighted cox2 MP), Contracaecum taxa did not form a clade with the other Anisakidae. For the rDNA gene tree, the relationship of Contracaecum was equivocal as assessed by statistical comparisons of alternative topologies (Nadler and Hudspeth, 1998). Likewise, in equal- and transversion-weighted bootstrap MP analysis of $\operatorname{cox} 2$, Contracaecum was unresolved among the ingroup taxa. So although the best single estimate of phylogeny (the combined evidence tree) yielded a monophyletic Anisakidae, support for this clade appears to be weak given these data.

In the transversion-weighted $\operatorname{cox} 2$ gene tree, a clade was recovered that included Anisakinae, Contracaecinae, and Goezia, consistent with representation of Goezia as a subfamily within the Anisakidae (Hartwich, 1974; Gibson, 1983). In contrast, this grouping of Goezia with the anisakids was not recovered in the transversion-weighted bootstrap tree, and Goezia was included among the Raphidascarididae with high (99\%) bootstrap support in the combined evidence tree. Furthermore, for the combined evidence, the shortest alternative tree depicting $G$. pelagia within the Anisakidae was significantly worse (requiring 45 additional steps), indicating that both the most parsimonious explanation of the combined data and statistical evaluation refutes inclusion of Goezia with the anisakids.

Like previous analyses of rDNA data, or the combined analysis of rDNA and morphology (Nadler, 1992; Nadler and Hudspeth, 1998), the combined evidence tree did not yield robust support for relationships among more distantly related ascaridoid clades as inferred from bootstrap parsimony analysis. Thus, although the single tree inferred from combined evidence is the best explanation of these data, some of the deeper nodes in this tree should be interpreted cautiously. Given this caveat, the combined evidence tree does not support the hypothesis that ascaridoids of marine mammal definitive hosts are most closely related to species maturing in marine fish (Osche, 1963). However, unlike results for rDNA alone (Nadler and Hudspeth, 1998), the combined evidence tree is consistent with the hypothesis that parasites of piscivorous aquatic mammals and birds are more closely related to those from terrestrial mammalian hosts, than those maturing in bony fish (Anderson, 1984). With respect to definitive host, neither taxa maturing in mammals nor those from all aquatic hosts are monophyletic; only species maturing in fish form a clade. The combined evidence tree does not appear consistent with the hypothesis of a broad pattern of ascaridoid host-parasite coevolution (Osche, 1958, 1963). It seems more likely that these host-parasite associations reflect a variety of complex patterns of definitive host acquisition with subsequent speciation, including reaching novel hosts via transfer from prey hosts to predator hosts through the food chain (Sprent, 1982, 1992), or, conversely, transfers from predator hosts to prey hosts via precocity (Anderson and Bartlett, 1993).

Only recently have investigators provided explicit phylogenetic proposals for relationships among ascaridoid genera (Nadler, 1992, 1995; Nadler and Hudspeth, 1998). In the combined evidence tree, moderate $(69 \%)$ bootstrap support was observed for a clade consisting of Anisakis and Pseudoterranova, species that use marine mammals as definitive hosts. The clade con- sisting of Ascaris and Parascaris was reliably supported (88\%) by bootstrap resampling, and the shortest alternative topology (16 more steps) without the Ascaris-Parascaris clade was significantly worse by statistical tests. Topologies that did not preserve this clade were also significantly worse for the rDNA data alone (Nadler and Hudspeth, 1998). The Ascaris-Parascaris clade is unexpected based on morphological dissimilarities of gross labial features. It appears likely that the labial differences of Parascaris and Ascaris, which occur late during larval development (Pilitt et al., 1979, 1981), are an example of heterochrony.

In the combined evidence tree, extremely strong bootstrap support $(100 \%)$ was observed for the Ascaridinae, and within this clade, monophyly of Ascaris, Parascaris, and Baylisascaris received moderate support $(77 \%)$. The Baylisascaris species were also monophyletic with moderate (77\%) bootstrap support. Some trees based on rDNA have provided evidence for Baylisascaris monophyly (Nadler, 1992), whereas trees based on other regions of rDNA sequence have not (Nadler and Hudspeth, 1998). Inferred substitutions from analysis of cox2 support Baylisascaris monophyly in all most parsimonious trees (73\% of bootstrap MP trees in unweighted analysis; $62 \%$ in transversion-weighted analysis).

Several cryptic species of Anisakis have been identified by allozyme electrophoresis (Nascetti et al., 1986). Clones of $28 \mathrm{~S}$ rDNA obtained from pooled juvenile samples also revealed unexpected sequence divergence consistent with multiple species (Nadler and Hudspeth, 1998). The 2 cox 2 clones representing Anisakis also appeared to represent separate species. With respect to the combined tree, clone 1 had 6 autapomorphies, whereas clone 4 had 5 autapomorphies, and there were a total of $15 \mathrm{nt}$ differences between these clones. These clones were treated separately for inferring the cox 2 gene tree, and as expected, they were monophyletic (with $100 \%$ bootstrap support). Anisakis juveniles of different species are morphologically quite similar, and sequence data (such as rDNA or mtDNA) or sequence-specific tests (e.g., PCR-restriction fragment length polymorphism, SSCP) correlated with morphologically or biochemically diagnosed adults may provide the only practical method for identification of juveniles.

The validity of human and pig Ascaris as separate species has remained controversial (Gibson, 1983; Anderson et al., 1993; Anderson and Jaenike, 1997). Studies of human and pig Ascaris using restriction site data (Anderson et al., 1993; Anderson, Romero-Abal et al., 1995; Anderson and Jaenike, 1997) have not revealed a single genetic marker that distinguishes host-associated Ascaris, yet interpretation of data representing multilocus genotypes is consistent with the inference of restricted gene flow between these putative species. Addressing the species status of host-associated Ascaris taxa with sequence data requires population-level sampling that was not done in the current study. However, it is noteworthy that for the combined evidence tree, A. lumbricoides had 7 unambiguous autapomorphies (6 rDNA characters, 1 cox 2 character) and A. suum had 1 such autapomorphy (a rDNA character). This suggests that rDNA sequences may provide useful data for evaluating species status of Ascaris in a phylogenetic context (Adams, 1998), although regions of rDNA with more rapid rates of change are likely to provide greater phylogenetic resolution for this question. In a nonphylogenetic context, the pig- and hu- 
man-derived specimens had 2 nucleotide differences for $\operatorname{cox} 2$, both transitions $(A-G)$ at third positions of codons that were silent at the amino acid level. The rDNA sequences had a total of $7 \mathrm{nt}$ differences for the pig- and human-derived worms (Nadler and Hudspeth, 1998). For both LSU rDNA and cox2 sequences, A. suum and A. lumbricoides had the smallest pairwise distance among taxa in the comparisons. These results are consistent with other observations of low genetic differentiation between these host-associated taxa (Nascetti et al., 1979; Nadler, 1987; Anderson et al., 1993).

Unlike analysis of rDNA (for which $H$. fortalezae and $H$. reliquens received strong bootstrap support), or $\operatorname{cox} 2$ (for which $H$. pelagicum and $H$. reliquens received strong bootstrap support), no sister taxa within the Raphidascarididae received even moderate bootstrap support in the combined evidence tree, presumably due to character conflicts resulting from combining the molecular data. The conflict between inferred Hysterothylacium sister taxa from separate analyses of rDNA (Fig. 2) and cox2 (Figs. 3, 4) represents the only instance where these different loci strongly support conflicting clades. One potential explanation is that this difference reflects discordance between the histories of rDNA and the mitochondrial genome. An alternative is that elements of sequence evolution, such as the comparatively long branches in the mitochondrial gene tree may be misleading the parsimony analysis. An argument against the latter explanation is that $H$. pelagicum and $H$. reliquens are also sister taxa in maximum-likelihood analysis of the cox 2 data (data not shown), and likelihood inference is less sensitive to long-branch attraction (Felsenstein, 1981).

\section{Character evolution}

Patterns of character evolution, as explored using the combined evidence tree, suggest that certain features that have been used to develop evolutionary scenarios and classifications represent either plesiomorphic states or highly homoplastic characters. As examples of the former, the left-right filamental $(\mathrm{H}-$ shaped) excretory system and the presence of a ventriculus, features emphasized by several investigators as indicators of relationship (Gibson, 1983; Sprent, 1983), are both plesiomorphic character states. Likewise, presence or absence of the intestinal cecum has been emphasized as a key feature by certain workers (Hartwich, 1954), yet mapping indicates that this character is highly homoplasious.

Parsimony analysis revealed putative morphological synapomorphies with respect to the combined evidence tree (Fig. 5 ). For example, states of 2 characters (left-glandular excretory system, excretory pore between lips) are synapomorphic for the Anisakidae. The Anisakinae are defined by 3 morphological synapomorphies (presence of caudal plates, ventriculus long, reduced lips), the Ascaridinae by 1 (ventriculus absent), and the Raphidascarididae by 1 (excretory system left-filamental). Excretory system structure, which is complex and variable among taxa, has been considered an important character for developing evolutionary hypotheses (Hartwich, 1954, 1957; Gibson, 1983; Sprent, 1983). Similarly, Fagerholm (1991) proposed that distribution patterns of cloacal papillae may also be useful for interpreting relationships. Although coding of cloacal papillae patterns may prove difficult, the combined tree supports Fagerholm's (1991) idea, in that the state of united distal papillae is apomorphic for Baylisascaris, Ascaris, and Parascaris, whereas the configuration of distal papillae in a more proximal position is apomorphic for Anisakis and Pseudoterranova. Inferences about synapomorphic morphological states based on trees obtained from analysis of combined evidence are likely to be particularly valuable for developing additional testable evolutionary hypotheses, because for certain rare taxa only morphological data are readily available.

Although COII amino acid sequences are not independent from their underlying nucleotide sequences (codons), parsimony mapping of deduced amino acids can reveal apomorphic patterns that are not evident when individual nucleotide sites are considered without reference to the genetic code. These amino acid replacements may also be viewed in light of functional constraints on COII evolution and previous comparative studies of COII sequences (Müller et al., 1988; Thomas and Wilson, 1991). Parsimony mapping of amino acid characters on the combined evidence tree revealed shared-derived patterns for clades (Figs. 1, 5). For example, the Raphidascarididae share a derived histidine for amino acid 50 of the alignment. Within this family, the clade composed of $H$. pelagicum, $H$. reliquens, I. inquies, and $G$. pelagia have a derived alanine at position 44 , and the sister taxa $H$. pelagicum and $H$. reliquens share a methionine at position 47. The Anisakinae share 2 derived amino acid states, isoleucine at position 69 and alanine at position 77 . Within this subfamily, the clade consisting of Anisakis and Pseudoterranova share a threonine at position 191, and the Anisakis taxa share a derived valine at position 185. The Ascaridinae have a shared-derived valine at position 151 , and within this subfamily, Baylisascaris spp., P. equorum, and Ascaris spp. have a synapomorphic valine at position 212 . The amino acid replacement at position 212 is chemically conservative (valine for isoleucine) but occurs at a site that appears to be virtually invariant based on comparison of sequences from diverse organisms (Müller et al., 1988). This is the only shared-derived replacement that occurs within the most highly conserved regions of COII (Fig. 1, shaded boxes). Thirty-five autapomorphic amino acid replacements occur relative to the combined tree; 5 of these occur within highly conserved regions, and all of these are chemically conservative replacements.

Although the life cycles of many ascaridoids are not known in detail, available information indicates substantial variation in potential transmission patterns, ranging from monoxenous life cycles requiring no intermediate host, e.g., Ascaris, Parascaris, and certain Baylisascaris, to heteroxenous patterns requiring intermediate hosts and involving paratenesis, e.g., Anisakis. Certain authorities have regarded the monoxenous pattern (and typically nematodes with such life cycles) as ancestral (Chitwood and Chitwood, 1950; Mozgovoi, 1953). Other investigators (Fülleborn, 1927; Sprent, 1954; Chabaud, 1955; Anderson, 1988) have proposed that heteroxeny is ancestral for ascaridoids, with the direct life-cycle pattern of Ascaris, which involves somatic and tracheal migrations, representing loss of intermediate hosts, i.e., secondary monoxeny (Fülleborn, 1927; Chabaud, 1955; Anderson, 1988). In the combined evidence tree, ascaridoid species with classical secondary monoxeny (Ascaris, Parascaris) are a clade within the Ascaridinae, some with facultative monoxenous patterns, i.e., where somatic/tracheal migrations can yield patent infections (even though most infections are acquired through other routes) are sister to this clade, 
and others with modified facultative monoxeny, i.e., T. leonina, branch earlier, consistent with Fülleborn's (1927) hypothesis. Some species of Toxocara are also capable of facultative monoxeny, and strict interpretation of the combined evidence tree suggests that monoxeny evolved more than once within the Ascaridoidea. However, if the true evolutionary history is represented by a monophyletic Toxocarinae as the sister group to the Ascaridinae, a result not significantly worse than the combined evidence tree, then it is equivocal if the monoxenous pattern evolved more than once within the superfamily.

\section{ACKNOWLEDGMENTS}

We thank J. Brattey, B. Font, K. Gasser, R. Overstreet, R. Palmer, and J. Sakanari for help collecting specimens. We are grateful to M. Hudspeth for help with troubleshooting sequencing reactions. H.-P. Fagerholm and E. Hoberg provided information on morphological characters. This work was supported in part by National Science Foundation grant DEB-9208024.

\section{LITERATURE CITED}

ADAMS, B. J. 1998. Species concepts and the evolutionary paradigm in modern nematology. Journal of Nematology 30: 1-21.

ANDERSON, R. C. 1984. The origins of zooparasitic nematodes. Canadian Journal of Zoology 62: 317-328.

1988. Nematode transmission patterns. Journal of Parasitology 74: $30-45$.

, AND C. M. BARLETT. 1993. The significance of precocity in the transmission of the nematode parasites of vertebrates. Canadian Journal of Zoology 71: 1917-1922.

ANDERSON, T. J. C., AND J. JAENIKE. 1997. Host specificity, evolutionary relationships and macrogeographic differentiation among Ascaris populations from humans and pigs. Parasitology 115: 325-342.

—, R. Komuniecki, P. R. Komuniecki, AND J. JAenike. 1995. Are mitochondria inherited paternally in Ascaris? International Journal for Parasitology 25: 1001-1004.

, M. E. Romero-Abal, And J. JaEnike. 1993. Genetic structure and epidemiology of Ascaris populations: Patterns of host affiliation in Guatemala. Parasitology 107: 319-334.

- $\longrightarrow$ AND $\longrightarrow$ 1995. Mitochondrial DNA and Ascaris microepidemiology: The composition of parasite populations from individual hosts, families and villages. Parasitology 110: 221-229.

Ausubel, F. M., R. Brent, R. E. Kingston, D. D. Moore, J. G. SeidMAN, J. A. Smith, AND K. STRUHL. 1989. Short protocols in molecular biology. Greene Publishing Associates and Wiley-Interscience, New York, New York, 387 p.

BAIRD, W. 1853. Descriptions of some new species of entozoa from the collection of the British Museum. Proceedings of the Zoological Society of London 248: 18-25.

Beaver, P. C. 1956. Larva migrans. Experimental Parasitology 5: 587621.

Bisson, R., G. C. M. Steffens, And G. Buse. 1982. Localization of lipid binding domain(s) on subunit II of beef heart cytochrome $c$ oxidase. Journal of Biological Chemistry 257: 6716-6720.

Blouin, M. S., C. A. Yowell, C. H. Courtney, and J. B. Dame. 1998. Substitution bias, rapid saturation, and the use of mtDNA for nematode systematics. Molecular Biology and Evolution 15: 17191727.

Boveri, T. 1899. Die Entwicklung von Ascaris megalocephala mit besonder Rücksicht an die Kernverhältnisse. Festschrift Kupfer, p. $283-340$.

Chabaud, A. G. 1955. Essai d'interpretation phylétique des cycles évolutifs chez les nématodes parasites de vertébrés. Conclusions taxonomiques. Annales de Parasitologie Humaine et Comparee 30: 83-126.

1965. Ordre des Ascaridida. In Traite de zoologie: Anatomie, systematique, biologie, P. P. Grasse (ed.). Masson et cie, Paris, France, p. 932-1025.

Chitwood, B. G., AND M. B. Chitwood. 1950. An introduction to nem- atology. Section 1. Anatomy. B. G. Chitwood, Baltimore, Maryland, $213 \mathrm{p}$.

Clary, D. O., and D. R. Wolstenholme. 1985. The mitochondrial DNA molecule of Drosophila yakuba: Nucleotide sequence, gene organization, and genetic code. Journal of Molecular Evolution 22: 252-271.

Crandall, K. A., And J. F. FitZPatrick, JR. 1996. Crayfish molecular systematics: Using a combination of procedures to estimate phylogeny. Systematic Biology 45: 1-26.

DeARDORFF, T. L., AND R. M. OverstreEt. 1980. Review of Hysterothylacium and Iheringascaris (both previously = Thynnascaris) (Nematoda: Anisakidae) from the northern Gulf of Mexico. Proceedings of the Biological Society of Washington 93: 1035-1079.

Eernisse, D. J., AND A. G. KLuge. 1993. Taxonomic congruence versus total evidence, and amniote phylogeny inferred from fossils, molecules, and morphology. Molecular Biology and Evolution 10: $1170-1195$.

FAGERHOLM, H.-P. 1989. Intra-specific variability of the morphology in a single population of the seal parasite Contracaecum osculatum (Rudolphi) (Nematoda: Ascaridoidea), with a redescription of the species. Zoologica Scripta 18: 33-41.

. 1991. Systematic implications of male caudal morphology in ascaridoid nematode parasites. Systematic Parasitology 19: 215 228.

Felsenstein, J. 1981. Evolutionary trees from DNA sequences: A maximum likelihood approach. Journal of Molecular Evolution 17: 368-376.

FooR, W. E. 1970. Spermatozoan morphology and zygote formation in nematodes. Biology of Reproduction (Suppl.) 2: 177-202.

FüLLEBORN, F. 1927. Ueber das Verhalten der Larven von Strongyloides stercoralis, Hakenwürmern und Ascaris lumbricoides im Körper des Wirtes und ein Versuch, es biologisch zu deuten. Beihefte (2). Archiv für Schiffs and Tropenhygiene 31: 151-202.

GiBson, D. I. 1983. The systematics of ascaridoid nematodes-A current assessment. In Concepts in nematode systematics, A. R. Stone, H. M. Platt, and L. F. Khalil (eds.). Academic Press, New York, New York, p. 321-338

Hartwich, G. 1954. Die Vorderarmstrukturen, das Exkretionssytem sowie der Kopfbau der Ascariden und ihre taxonomische Bedeutung. Wissenschaftliche Martin-Luther-Universitaet Halle-Wittenberg Mathematish Naturwissenschaftliche Reihe 3: 1171-1212.

. 1957. Zur Systematik der Nematoden-Superfamilie Ascaridoidea. Zoologische Jahrbücher Abteilung für Systematik, Ökologie und Geographie der Tiere 85: 211-252.

. 1974. Keys to genera of the Ascaridoidea. In CIH keys to the nematode parasites of vertebrates, R. C Anderson, A. G. Chabaud, and S. Wilmott (eds.). Commonwealth Agricultural Bureaux, Farnham Royal, U.K., p. 1-15.

Higgins, D. E., A. J. Bleasby, and R. Fuchs. 1992. Clustal V: Improved software for multiple sequence alignment. Computer Applications in the Biosciences 8: 189-191.

Holm, L., M. Saraste, AND M. Wikstrom. 1987. Structural models of the redox centres in cytochrome oxidase. The EMBO Journal 6: 2819-2823.

Hsu, H. F. 1933. Study on the oesophageal glands of parasitic nematode superfamily Ascaroidea. Chinese Medical Journal 47: 1247-1288.

Hugall, A., J. Stanton, and C. Moritz. 1997. Evolution of the ATrich mitochondrial DNA of the root knot nematode Meloidogyne hapla. Molecular Biology and Evolution 14: 40-48.

Hugot, J. P., S. Morand, AND M. VASSART. 1991. Morphological study of Contracaecum magnicollare (Nematoda, Anisakidae) from Anous minutus (Aves, Laridae). Systematic Parasitology 20: 229-236.

Huizinga, H. 1967. The life cycle of Contracaecum multipapillatum (Von Drasche, 1882) Lucker, 1941 (Nematoda: Heterocheilidae). Journal of Parasitology 53: 368-375.

Hyman, B. C., AND J. L. B. AzEvedo. 1996. Similar evolutionary patterning among repeated and single copy nematode mitochondrial genes. Molecular Biology and Evolution 13: 221-232.

INGLIS, W. G. 1965. Patterns of evolution in parasitic nematodes. In Evolution of parasites, A. E. R. Taylor (ed.). Blackwell Scientific Publications, Oxford, U.K., p. 79-124.

Jermitn, L. S., D. Graur, AND R. H. Crozier. 1995. Evidence from analyses of intergenic regions for strand-specific directional muta- 
tion pressure in metazoan mitochondrial DNA. Molecular Biology and Evolution 12: 558-563.

Jones, R. E., F. D. Finkelman, R. B. Hester, And S. G. Kayes. 1994. Toxocara canis: Failure to find IgE receptors (Fc-epsilon- $\mathrm{R})$ on eosinophils from infected mice suggest that murine eosinophils do not kill helminth larvae by an IgE-dependent mechanism. Experimental Parasitology 78: 64-75.

JuKES, T. H., AND V. BHUSHAN. 1986. Silent nucleotide substitutions and $\mathrm{G}+\mathrm{C}$ content of some mitochondrial and bacterial genes. Journal of Molecular Evolution 24: 39-44.

Kageyama, T. 1998. Molecular cloning, expression and characterization of an Ascaris inhibitor for pepsin and cathepsin E. European Journal of Biochemistry 253: 804-809.

KAZACOS, K. R. 1986. Raccoon ascarids as a cause of larva migrans. Parasitology Today 2: 253-255.

Keddie, E. M., T. HigazI, AND T. R. UnNASCh. 1998. The mitochondrial genome of Onchocerca volvulus: Sequence, structure and phylogenetic analysis. Molecular and Biochemical Parasitology 95: 111127.

Klöser, H., J. Plötz, H. Palm, A. Bartsch, and G. Hubold. 1992. Adjustment of anisakid nematode life cycles to the high Antarctic food web as shown by Contracaecum radiatum and C. osculatum in the Weddell sea. Antarctic Science 4: 171-178.

KLugE, A. G. 1998. Total evidence or taxonomic congruence: Cladistics or consensus classification. Cladistics 14: 151-158.

KøIE, M., AND H.-P. FAGERHOLM. 1995. The life cycle of Contracaecum osculatum (Rudolphi, 1802) sensu stricto (Nematoda, Ascaridoidea, Anisakidae) in view of experimental infections. Parasitology Research 81: 481-489.

KomunieCKi, P. R., J. Johnson, M. KAMHAwi, AND R. KomunieCKi. 1993. Mitochondrial heterogeneity in the parasitic nematode, Ascaris suum. Experimental Parasitology 76: 424-437.

energy metabolism during the development of the parasitic nematode Ascaris suum. In Molecular approaches to parasitology, J. C. Boothroyd and R. Komuniecki (eds.). Wiley-Liss, New York, New York, p. 109-121.

Maddison, W. P., AND D. R. MAdDison. 1992. MacClade. Analysis of phylogeny and character evolution, version 3. Sinauer Associates, Sunderland, Massachusetts, $404 \mathrm{p}$.

Mozgovor, A. A. 1953. Study of phylogenetic relationships and evolutionary pathways of ascaridates. In Contributions to helminthology (Israel Program for Scientific Translations, Jerusalem, 1966). Izdatel'stvo Akademii Nauk SSSR, Moskva, p. 425-434.

Müller, M., B. SchläPfER, AND A. AzzI. 1988. Cytochrome c oxidase from Paracoccus denitrificans: Both hemes are located in subunit I. Proceedings of the National Academy of Sciences, USA 85: 6647-6651.

Murrell, K. D., L. Eriksen, P. Nansen, H.-C. Slotved, and T. RasMUSSEN. 1997. Ascaris suum: A revision of its early migratory path and implications for human ascariasis. Journal of Parasitology 83: 255-260.

NADLER, S. A. 1987. Biochemical and immunological systematics of some ascaridoid nematodes: Genetic divergence between congeners. Journal of Parasitology 73: 811-816.

- 1992. Phylogeny of some ascaridoid nematodes, inferred from comparison of $18 \mathrm{~S}$ and $28 \mathrm{~S}$ rRNA sequences. Molecular Biology and Evolution 9: 932-944.

-1995. Advantages and disadvantages of molecular phylogenetics: A case study of ascaridoid nematodes. Journal of Nematology 27: 423-432.

- 1996. Microevolutionary patterns and molecular markers: The genetics of geographic variation in Ascaris suum. Journal of Nematology 28: 277-285.

$\longrightarrow$, AND D. S. S. HUDSPETH. 1998. Ribosomal DNA and phylogeny of the Ascaridoidea (Nemata: Secernentea): Implications for morphological evolution and classification. Molecular Phylogenetics and Evolution 10: 221-236.

Nascetti, G., R. Cianchi, S. Mattiucci, S. D’Amelio, P. Orecchia, L. Paggi, J. Brattey, B. Berland, J. W. Smith, and L. Bullini. 1993. Three sibling species within Contracaecum osculatum (Nematoda, Ascaridida, Ascaridoidea) from the Atlantic arctic-boreal region:
Reproductive isolation and host preferences. International Journal for Parasitology 23: 105-120.

—, C. Grappelli, L. Bullini, and S. G. Montalenti. 1979. Ricerche sul differnziamento genetico di Ascaris lumbricoides e Ascaris suum. Atti della Accademia Nazionale dei Lincei Rendiconti classe di Scienze Fisiche Matematiche e Naturali 67: 457-465.

- , L. Paggi, P. Orecchia, J. W. Smith, S. Mattiucci, and L. Bullini 1986. Electrophoretic studies on the Anisakis simplex complex (Ascaridida: Anisakidae) from the Mediterranean and the North East Atlantic. International Journal for Parasitology 16: 633640.

Neuhaus, H., F. Mueller, A. EtTer, And H. Tobler. 1987. Type I-like intervening sequences are found in the rDNA of the nematode Ascaris lumbricoides. Nucleic Acids Research 15: 7689-7707.

Okimoto, R., J. L. Macfarlane, D. O. Clary, and D. R. WolstenHOLME. 1992. The mitochondrial genomes of two nematodes, Caenorhabditis elegans and Ascaris suum. Genetics 130: 471-498.

Osche, G. 1958. Beitrage zur morphologie, okologie und phylogenie der Ascaridoidea (Nematoda): Parallelen in der evolution von parasit und wirt. Zeitschrift für Parasitenkunde 18: 479-572.

. 1963. Morphological, biological, and ecological considerations in the phylogeny of parasitic nematodes. In The lower metazoa, comparative biology and phylogeny, E. C. Dougherty (ed.). University of California Press, Berkeley, p. 283-302.

Overholtzer, M. H., P. S. Yakowec, and V. Cameron. 1996. The effect of amino acid substitutions in the conserved aromatic region of subunit II of cytochrome c oxidase in Saccharomyces cerevisiae. Journal of Biological Chemistry 271: 7719-7724.

Overstreet, R. M., AND G. W. Meyer. 1981. Hemorrhagic lesions in stomach of rhesus monkey caused by a piscine ascaridoid nematode. Journal of Parasitology 67: 226-235.

Paggi, L., G. Nascetti, R. Cianchi, P. Orecchia, S. Mattiucci, S. D'Amelio, B. Berland, J. Brattey, J. W. Smith, and L. Bullini. 1991. Genetic evidence for three species within Pseudoterranova decipiens (Nematoda, Ascaridida, Ascaridoidea) in the north Atlantic and Norwegian and Barents seas. International Journal for Parasitology 21: 195-212.

PilitT, P. A., J. R. Lichtenfels, And P. A. Madden. 1979. Differentiation of fourth and early fifth stages of Parascaris equorum (Goeze, 1782) Nematoda: Ascaridoidea. Proceedings of the Helminthological Society of Washington 46: 15-20.

, tion of late fourth and early fifth stages of Ascaris suum Goeze, 1782 (Nematoda: Ascaridoidea) in swine. Proceedings of the Helminthological Society of Washington 48: 1-7.

Prager, E. M., AND A. C. WiLson. 1988. Ancient origin of lactalbumin from lysozyme: Analysis of DNA and amino acid sequences. Journal of Molecular Evolution 27: 326-335.

RAilliet, A., AND A. Henry. 1912. Quelques nématodes parasites des reptiles. Bulletin de la Societe de Pathologie Exotique et de ses Filiales 4: 251-259.

Sanderson, M. J., M. J. Donoghue, W. Piel, and T. Eriksson. 1994. TreeBASE: A prototype database of phylogenetic analyses and an interactive tool for browsing the phylogeny of life. American Journal of Botany 81: 183.

SAZ, H. J., AND A. WEIL. 1960. The mechanism of formation of $\alpha-$ methylbutyrate from carbohydrate by Ascaris lumbricoides muscle. Journal of Biological Chemistry 235: 914-918.

Sprent, J. F. A. 1954. The life cycles of nematodes in the family Ascarididae Blanchard 1896. Journal of Parasitology 40: 608-617.

. 1982. Host-parasite relationships of ascaridoid nematodes and their vertebrate hosts in time and space. Deuxième Symposium sur la Spécificité Parasitaire des Parasites des Vertébrés. Memoires du Muséum National d'Histoire Naturelle Serie A, Zoologie 123: 255263.

1983. Observations on the systematics of ascaridoid nematodes. In Concepts in nematode systematics, A. R Stone, H. M. Platt, and L. F. Khalil (eds.). Academic Press, New York, New York, p. 303-319.

. 1992. Parasites lost? International Journal for Parasitology 22: $139-151$.

SuEOKA, N. 1992. Directional mutation pressure, selective constraints, and genetic equilibria. Journal of Molecular Evolution 34: 95-114. 
SWOFFORD, D. L. 1993. Phylogenetic analysis using parsimony, version 3.1.1. Illinois Natural History Survey, Urbana, Illinois, 257 p.

Templeton, A. R. 1983. Phylogenetic inference from restriction endonuclease cleavage site maps with particular reference to the humans and apes. Evolution 37: 221-244.

. 1996. Contingency tests of neutrality using intra/interspecific gene trees: The rejection of neutrality for the evolution of the mitochondrial cytochrome oxidase II gene in hominoid primates. Genetics 144: 1263-1270.

Thomas, W. K., AND A. C. WiLson. 1991. Mode and tempo of molecular evolution in the nematode Caenorhabditis: Cytochrome oxidase II and calmodulin sequences. Genetics 128: 269-279.

Von BenEDEN, E. 1883. Recherches sur la fécondation et la maturation. Archives de Biologie 4: 265-641.
Wolfe, K. H., P. M. Sharp, AND W.-H. Li. 1989. Mutation rates differ among regions of the mammalian genome. Nature 337: 283-285.

Wolstenholme, D. R., J. L. Macfarlane, R. OKimoto, D. O. Clary, AND J. A. WAHLEITHNER. 1987. Bizarre tRNAs inferred from DNA sequences of mitochondrial genomes of nematode worms. Proceedings of the National Academy of Sciences USA 84: 1324-1328.

YANG, Z. 1997. PAML: A program package for phylogenetic analysis by maximum likelihood. Computer Applications in the Biosciences 12: $555-556$.

, AND S. Kumar. 1996. Approximate methods for estimating the pattern of nucleotide substitution and the variation of substitution rates among sites. Molecular Biology and Evolution 13: 650-659.

Zhu, X., R. B. GASser, AND N. B. Chilton. 1998. Differences in the 5.8S rDNA sequences among ascarid nematodes. International Journal for Parasitology 28: 617-622. 
J. Parasitol., 86(2), 2000 p. 394

(C) American Society of Parasitologists 2000

\section{ANNOUNCEMENT . .}

The $4^{\text {th }}$ International Symposium on Monogenea will be held 9-13 July 2001 in Brisbane, Queensland, Australia. Further details will be forthcoming. Contact persons are: Dr. Ian D. Whittington and Dr. Leslie A. Chisholm, Department of Microbiology and Parasitology, The University of Queensland, Brisbane, Qld. 4072, Australia.
Fax: +61733654620

Email: i.whittington@mailbox.uq.edu.au or 1.chisholm@mailbox-uq.edu.au

Web page: http://www.biosci.uq.edu.au/micro/academic/ianv/ism4.htm 